\title{
Information Flow Analysis of a Knowledge Mapping-Based System for University Alumni Collaboration: a Practical Approach
}

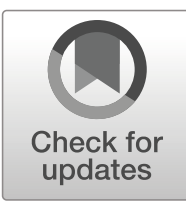

\author{
Bokolo Anthony $\mathrm{Jr}^{1}$
}

Received: 20 August 2019 / Accepted: 6 February 2020/ Published online: 15 February 2020

(C) The Author(s) 2020

\begin{abstract}
The aim of this study is to integrate knowledge mapping technique by applying information flow analysis to facilitate the collaboration between the university and its alumni by developing a knowledge mapping-based system based on a designed knowledge mapping model. Questionnaire was employed to collect data from respondents in a university to evaluate the applicability of the developed system. The collected data was further analyzed using Statistical Package for Social Sciences (SPSS). Descriptive and exploratory factor analysis was carried out to analyze the collected data by deploying test of normality, reliability, validity, and factor analysis. Results from descriptive analysis reveal that the developed system is applicable in facilitating alumni collaboration. Besides, results indicate that the developed system provides holistic and comprehensive knowledge support among alumni members to improve communication. Moreover, this study offers a methodological and comprehensive procedure to support interaction and provides information to alumni members. Theoretically, this study depicts how the designed knowledge mapping model defines, organizes, and develops procedural knowledge in order to explore and address communication inadequacy among alumni members. Practically, this study utilized knowledge mapping as a technique to visualize the source and flow of tacit and explicit knowledge for university alumni collaboration.
\end{abstract}

Keywords Knowledge management - Knowledge mapping · Information flow analysis · Data flow · Alumni collaboration · University alumni

Bokolo Anthony, Jr

anthony.j.bokolo@ntnu.no

1 Department of Computer Science, Norwegian University of Science and Technology, NTNU, 7491 Trondheim, Norway 


\section{Introduction}

Technological inventions over the web have rapidly grown through the years in many fields such as organizations and universities (Peterson and Roberts 2016). Hence, universities are deploying web services to improve their institutional activities such as alumni collaboration (Heckman and Guskey 1998; Leslie and Ramey, 1988). Furthermore, alumni collaboration system is a tool that provides an organized means through which alumni contribute and support to the continued growth and development of the university and to provide a lifelong opportunity for alumni to stay connected with each other and their alma mater (Leslie and Ramey, 1988). A well-structured alumni collaboration system offers the university an effective management of alumni activities (Weerts, Cabrera, and Sanford 2010). However, at the moment, several universities do not have an efficient and effective platform in controlling and managing alumni collaboration (Diamond and Kashyap 1997). Likewise, in the current alumni system, all processes and operations are done using a basic ad hoc application which do not completely support collaboration among alumni (Heckman and Guskey 1998). Additionally, the current approach utilized by universities involves a computerized system which is faced with limitations such as manual staff involvement and increased time required to maintain the system in tracking and communicating with alumni members for effective collaboration (Nayman et al. 1993).

To address these shortcomings, there is a need for a knowledge management technique that provides an organized medium through which alumni contribute and support to the continued growth and development of the university, and to provide a lifelong opportunity for alumni to stay connected with each other (Singer and Hughey 2002). Moreover, the knowledge management technique should provide a wellstructured model that provides universities with a proper control of their alumni and their activities to keep track of all alumni (Weerts et al. 2010). Accordingly, over the years several knowledge management techniques such as mind maps, information flow analysis, concept maps, social network analysis, knowledge mapping, etc. have been successfully applied for knowledge management in several domains as carried out by prior studies (Ferreira 2009; Mitchell and Seaman 2011; Sharif et al. 2014; Song and Zhao 2015; Liu and Cui 2017). However, prior studies (see Table 1) similar to this research predominantly focus on providing explicit knowledge to alumni members. These studies do not provide adequate tacit knowledge to facilitate collaboration in their research domain. Moreover, there are few studies that integrated knowledge management technique in improving university alumni collaboration.

Therefore, the contribution of this study is to integrate knowledge mapping to aid university alumni collaboration, where knowledge mapping is a knowledge management technique that aims to optimize the efficient and effective use of the institution's knowledge (Sumathy and Chidambaram 2014; Menaouer et al. 2015). Thus, developing a knowledge map involves locating important knowledge within the institution and then publishing some sort of list that shows where to access knowledge (Suresh and Egbu 2004; Dang et al., 2011; Jnr et al. 2016). To resolve the aforementioned issues, this study contributes to research and practice by integrating knowledge mapping to develop a system that provides operational information visualization for alumni collaboration to facilitate interaction and communication of student, alumni, staffs, and faculty members. Respectively, the following research questions are proposed to guide this study: 


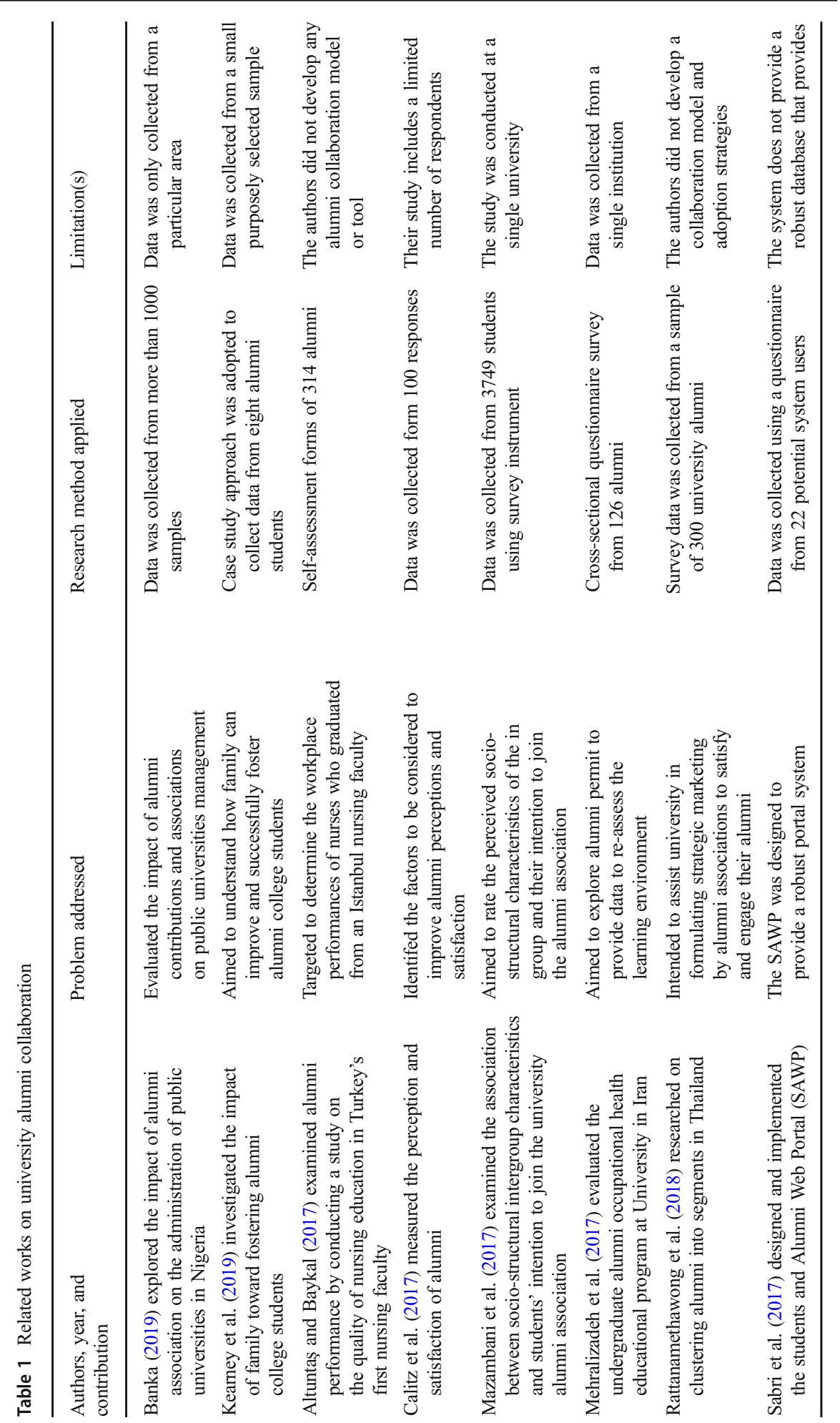




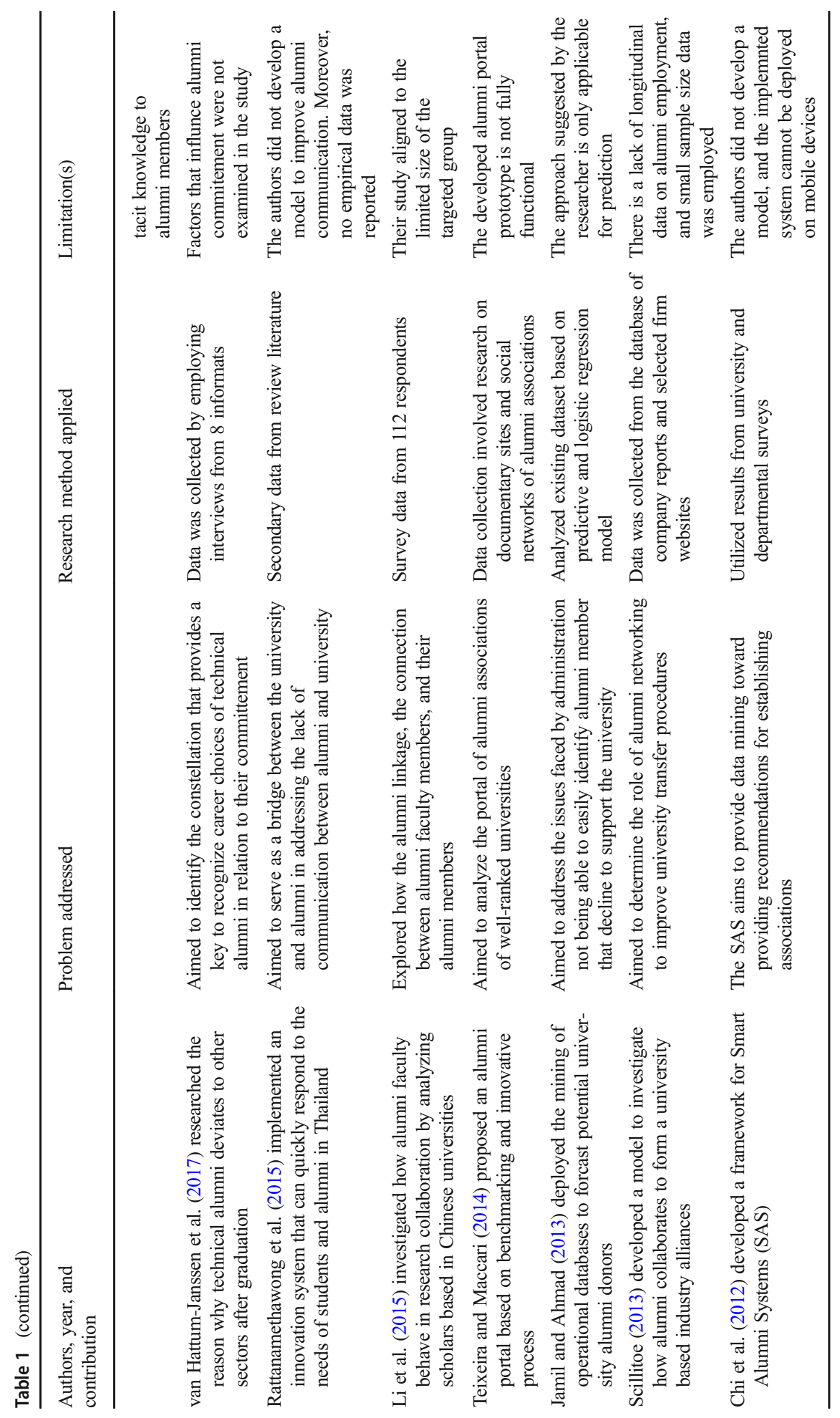




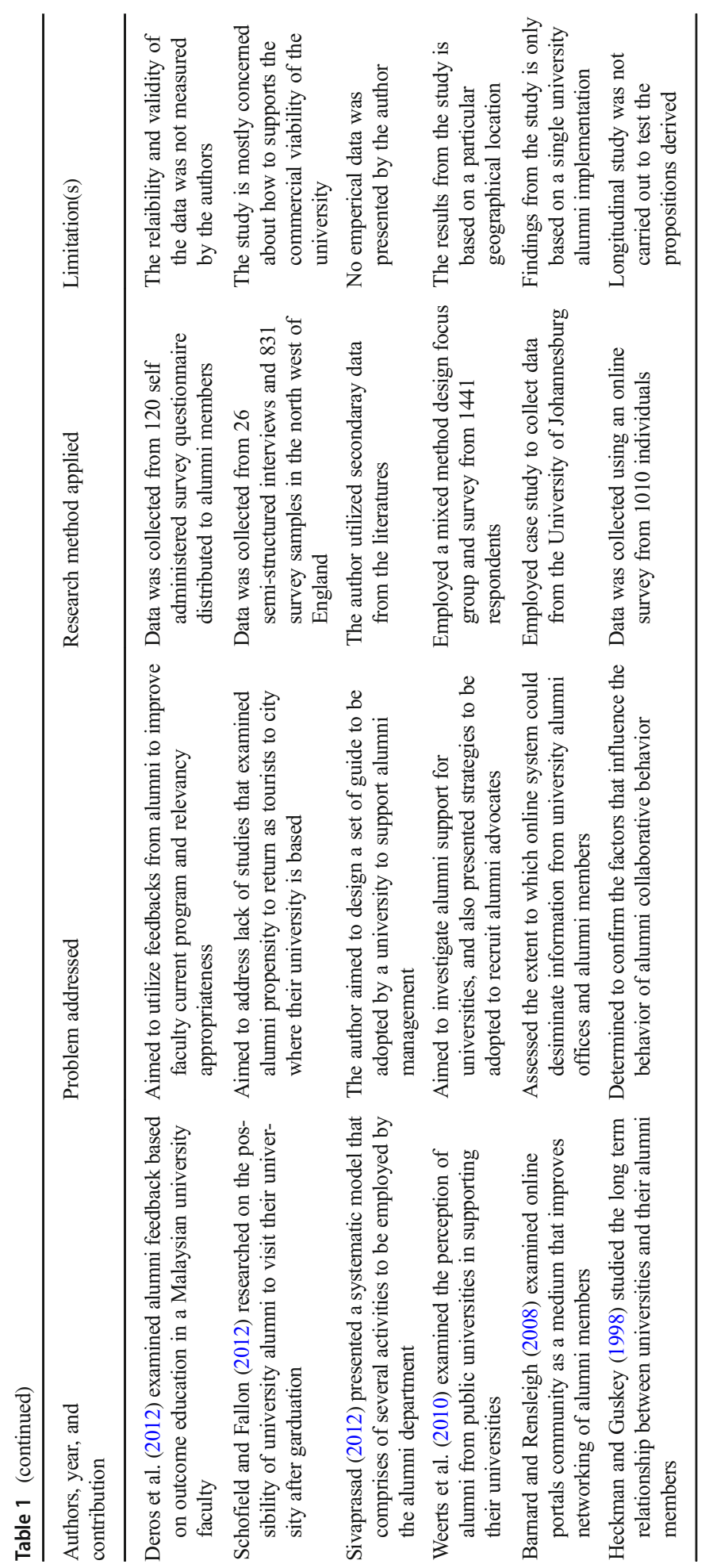


- How can knowledge mapping and information flow analysis be employed to facilitate management of university alumni collaboration?

- How to evaluate the applicability of the knowledge mapping-based system for alumni collaboration?

To answer these questions, this study designs a knowledge mapping model to provide blueprint to develop the knowledge mapping-based system. In addition, the applicability of the system is evaluated using questionnaire data analyzed using Statistical Package for Social Science (SPSS) version 23 for test of reliability, validity, normality, descriptive, and exploratory factor analysis. The organization of this paper is as follows: The literature review is presented in section 2, the methodology has been presented in section 3, system evaluation is presented in section 4 , the discussion is presented in section 5, implication of study is presented in section 6 , and lastly, the conclusion, limitations, and future works are presented in section 7.

\section{Literature Review}

This section discusses on background of current university alumni system, overview of web-based alumni system, overview of knowledge mapping technique, description of information flow analysis, related works, and the impact of explicit\# and tacit knowledge on alumni collaboration.

\section{Background of Current University Alumni System}

Universities currently implement online based system that is operated by a local server which is access using a web browser. The online based system can be access anywhere around the globe through the World Wide Web (WWW) (Mazambani et al. 2017). The system involves six steps as shown in Fig. 1.

Figure 1 shows the typical alumni system operations employed by the university in managing alumni activities. The current alumni system utilized by universities has minimal advantages because the system involves manual and online operations (Baade

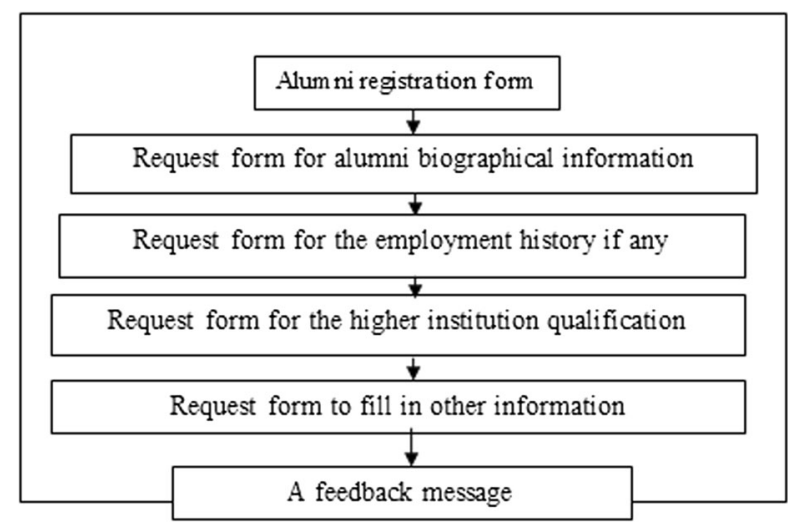

Fig. 1 Flow chart of a typical alumni system operations used by the university 
and Sundberg 1996). Besides, the current system is mostly involved in facilitating alumni registration. There are no additional functionalities that provide collaboration among alumni and the university. In addition, the current system does not provide effective interaction and communication between the university and alumni. The current system is time consuming, and it requires a lot of human effort to handle (Calitz et al. 2017). Moreover, there is lack of a message board for discussion where alumni can hold conversations in the form of posted message (Chi et al., 2012). Thus, there is a need for an approach that can address the aforementioned limitations faced in the current system.

\section{Overview of Web-Based Alumni System}

A web-based alumni system is an application that provides medium to access alumni or graduates of a school, college, or university. It refers to an online tool that facilitates communication among universities and alumni members. Moreover, a web-based alumni system provides alumnus with up-to-date information through the web. A typical architecture of a web-based alumni collaborative system is shown in Fig. 2.

Figure 2 depicts the architecture of a typical web-based alumni collaborative system that provides a medium for alumni to connect with current students and university staffs based on three layers which comprises of the interface, environment, and database tiers (Aldieri et al. 2018). Therefore, a web-based alumni collaborative system offers lifelong opportunity for alumni to stay connected with their fellow alumni (Heckman and Guskey 1998). The web-based alumni system provides services which improve professional and personal growth, to communicate the progress and plans of the university and to foster alumni involvement (Numprasertchai and Igel 2005). Besides,

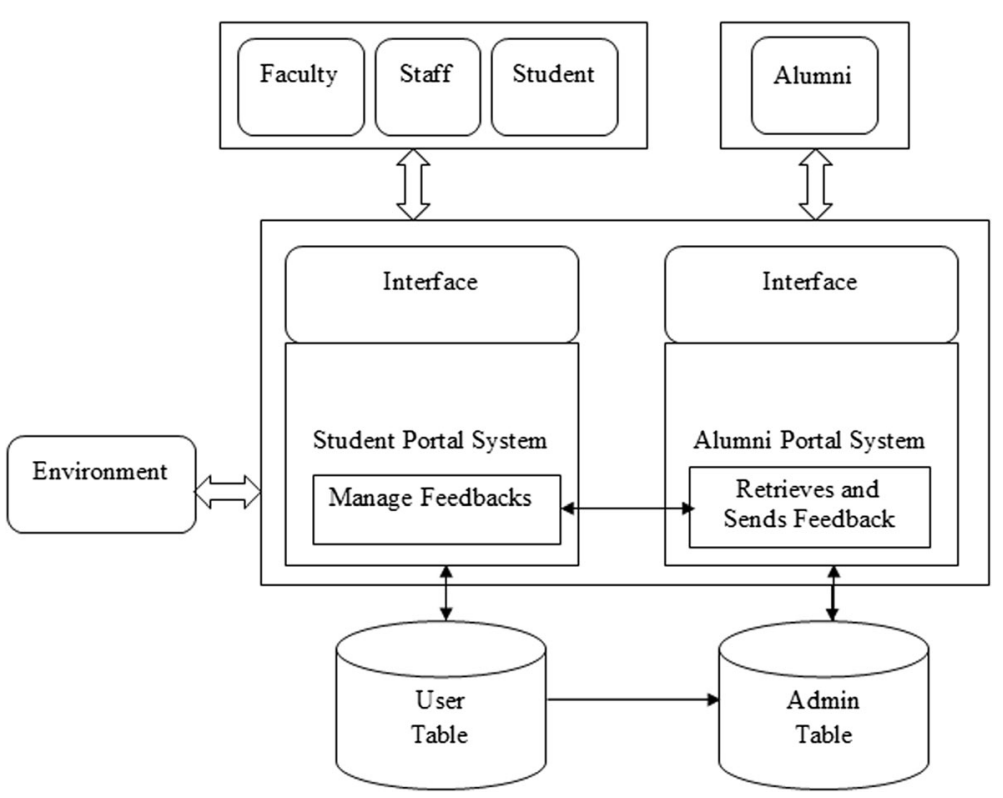

Fig. 2 Architecture of a typical web-based alumni collaborative system 
it supports active networking and linking of the university with alumni and promotes communication among the alumni in different year groups.

\section{Overview of Knowledge Mapping Technique}

Knowledge mapping refers to the process, methods, and tools for analyzing knowledge areas in order to discover features or meaning and to visualize knowledge in a comprehensive, transparent form such that the relevant features are clearly highlighted (Moradi et al. 2012; Menaouer et al. 2015). It can be defined as a process of surveying, assessing, and linking the information, knowledge, competencies, and proficiencies held by individuals and groups within an institution (Jnr et al. 2017). Also, knowledge mapping is a procedure which is used to manage knowledge in institution in order to utilize knowledge and improve communications (Balaid et al. 2013). In this regard knowledge mapping helps to use and share experts' tacit knowledge with others in order to improve effective learning (Dang et al. 2011). Knowledge mapping has become progressively important and has been employed in several domains.

Respectively, knowledge mapping offers holistic methods and procedure that can be utilized to support users in their search and exploration of knowledge, thereby providing crucial information (Wu et al. 2016). According to Dang et al. (2011), knowledge mapping is particularly significant in fast-growing domains where knowledge is created at an accelerating pace such as universities. In such domains, it is vital to develop and deploy advanced web-based approaches to facilitate desirable utilization by sifting through huge amounts of information and providing inclusive depictions of the complete knowledge (Jnr et al. 2016). Knowledge mapping can establish a relationship among students, faculty member, and alumni in university. Thus, knowledge mapping plays an important role in exchanging information among alumni and presents students to achieve the goal of collaboration (Eppler 2001; Dang et al. 2011). Hence, knowledge mapping allows comprehensive analyses and detailed understanding of university alumni collaboration development as shown in Fig. 3.

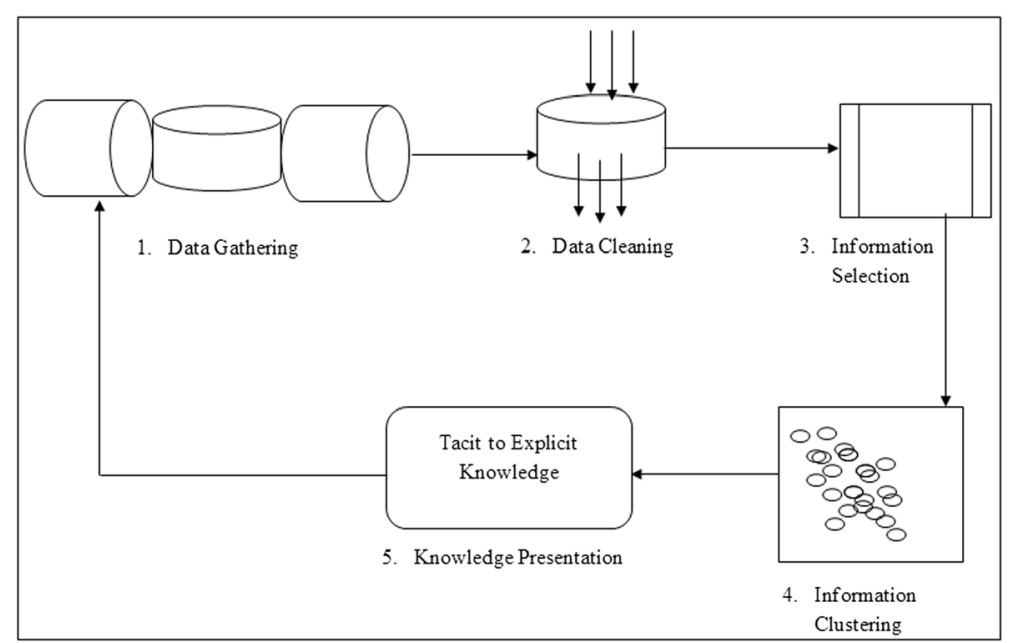

Fig. 3 Overview of knowledge mapping process 
Figure 3 shows an overview of knowledge mapping process which comprises of data gathering, data cleaning, information related feature selection, information clustering, and knowledge presentation. Therefore, knowledge mapping facilitates in building a framework for knowledge sharing (Aziz et al. 2011; Jnr and $\mathrm{Pa} 2016$ ). Each of the knowledge mapping process in Fig. 3 is described below;

\section{Data Gathering}

The required data about activities of university students, faculty staffs, alumni, and their interactions are gathered from a number of university databases. There may be several isolated data sources utilized in this step to collect data (Balaid et al. 2013; Moradi and Mirian, 2014).

\section{Data Cleaning}

As the raw data are unstructured, appropriate analysis and preprocessing methods are required to clean and complete the data (Moradi and Mirian 2014; Anthony Jr, 2019). This phase may remove duplicated data and employs redundant data check consistency, and other steps required to accurately input the data correctly (Jafari et al. 2009; Liu and Ge 2013).

\section{Information Selection}

Information may contain many fields that are not necessarily related to improve alumni collaboration (Liu and Ge 2013). So, this step involves verifying the semantics of features and selecting information required to improve alumni communication (Moradi and Mirian, 2014).

\section{Information Clustering}

According to the selected information in the previous step, the collected information can now form the core elements for information clustering (Qing-lan et al. 2016). This step can simply be performed by either clustering or categorization based on the type of data. In addition, clustering reveals lots of information to university students, faculty staffs, and alumni that need to find alumni information (Moradi and Mirian 2014).

\section{Knowledge Presentation}

This step presents different knowledge to university students, faculty staffs, and alumni (Liu and Ge, 2013; Moradi and Mirian 2014). Thus, clustered information is presented as knowledge to facilitate a specific alumni purpose such as improving collaboration and provision of information on alumni members (Jafari et al. 2009; Talab et al. 2018).

\section{Description of Information Flow Analysis}

Information is crucial in knowledge management, where information refers to a system of solution with context, interpretation, experience, and reflection. It possesses a 
descriptive value organization of data that is usable to be utilized to support decisionmaking. Similarly, Liang (2007) defined information flow analysis as any presentation of knowledge for the aim of eliciting, expanding, codifying, sharing, and using knowledge. Information flow analysis also depicts the advancement and associations of knowledge. Information flow analysis comprises conceptual knowledge relationships in chronological, associative, hierarchical, logical, causal, and evaluative presentation of knowledge flow (Liu and Cui 2017). Accordingly, Andrea (2006) stated that information flow analysis may be referred to as a map that presents how knowledge is acquired in an organization. Hence, information flow analysis is vital in developing a knowledge-based system. Likewise, Yun et al. (2011) mentioned that information flow analysis simplifies the flows, displays, constraints, and sources of knowledge within an institution. Correspondingly, Fig. 4 shows a detailed structure of information flow analysis for alumni collaboration.

Figure 4 depicts the structure of information flow analysis, where the red alphabets (A-D) show the stages of a typical information flow analysis procedure, whereas the numbers (1-8) show the stages of the flow of data. Besides, as seen in Fig. 4, a typical structure of an information flow analysis comprises of data capture (A), information discovery (B), tacit knowledge processing (C), and explicit knowledge presentation (D) as the main components of information flow analysis. Moreover, Fig. 4 shows how the domain expert which is the administrator inputs raw data that is captured (A) to the information generation stage to format data as clustered information as described in Fig. 3. Next, (B) is "information acquisition and extraction stage" to "tacit knowledge processing" (C) which involves tacit knowledge indexing and mapping which are saved to the knowledgebase. The saved data is utilized by current students, faculty staffs, and alumni members for collaboration as explicit knowledge presented through explicit knowledge visualization and application stage as mapped tacit converted to explicit knowledge to improve alumni collaboration and communication.

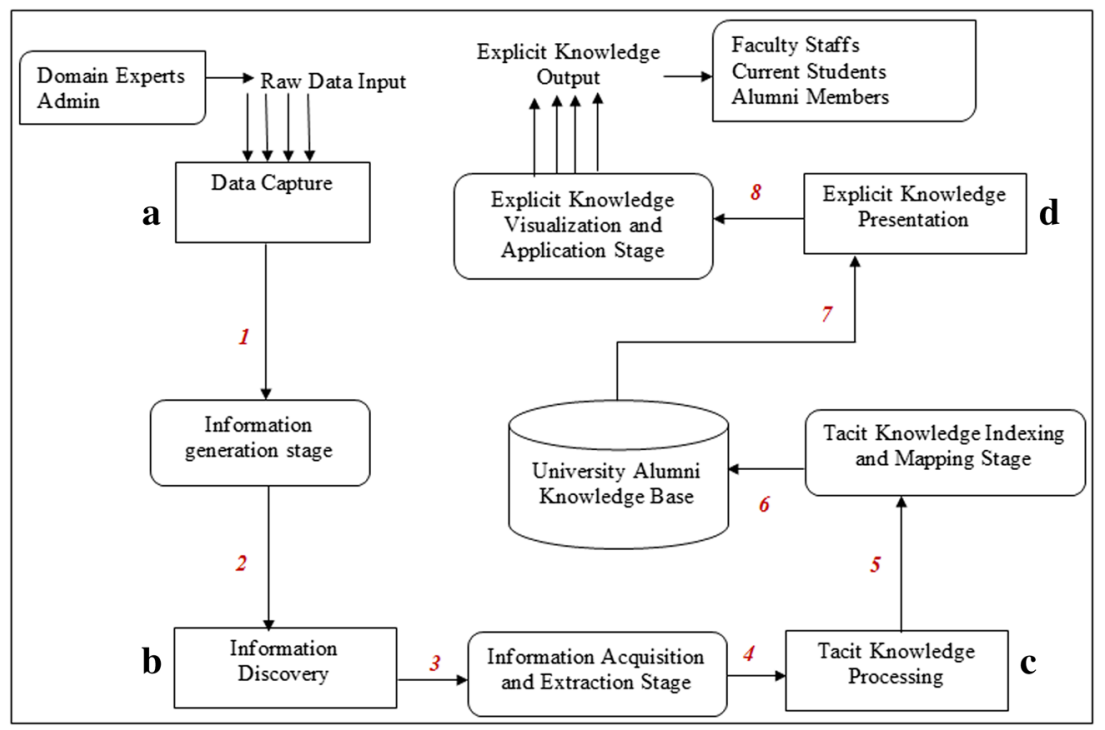

Fig. 4 Structure of an information flow analysis 
Furthermore, in this study communication is facilitated through knowledge presentation (D) which helps to transfer messages and notifications to alumni members in the developed system as information outputs. Therefore, information flow analysis helps to organize knowledge into interconnected facts which is useful for consolidating related information in a structured manner that simplifies understanding by showing the association between the information pieces (Andrea 2006). In addition, information flow analysis can be employed with strategies such as knowledge analogies, outlines, and frames. Information flow analysis depicts the structured layout and explanation of information (Yun et al. 2011). Therefore, this study has opted for information flow analysis as a type of knowledge mapping technique to be applied for university alumni collaboration, where this technique determines who is accessing what information resources (Liang 2007).

\section{Related Works}

Over the years several studies have been published that contributed to facilitate alumni university collaboration and communication. Accordingly, Table 1 reviews existing university alumni approaches proposed by prior studies.

Table 1 shows the prior studies aimed to improve alumni communication and collaboration. Findings from the reviewed studies in Table 1 suggest that the studies are mostly concerned with addressing factors that influence alumni communication and collaboration. However, some studies (Barnard and Rensleigh 2008; Chi et al., 2012; Deros et al. 2012; Jamil and Ahmad 2013; Teixeira and Maccari 2014; Scillitoe 2013; Rattanamethawong et al. 2015; Sabri et al., 2017) examined how to disseminate information. But, none of the studies integrated a technique to facilitate integration of tacit knowledge for collaboration among alumni members. Thus, there is a need for knowledge management technique such as knowledge mapping that can enhance the tacit knowledge dissemination among alumni members there by promoting coordination and of easy communication of students, alumni members, staffs, and faculty members.

\section{Impact of Explicit and Tacit Knowledge on Alumni Collaboration}

Prior approaches in Table 1 did not adequately provide tacit knowledge to alumni members which are knowledge that are difficult to capture and transfer. According to Ermine et al. (2006), there is a need for a critical knowledge mapping decision-based tool for achieving knowledge transfer actions from tacit to explicit knowledge. Ermine et al. (2006) mentioned that the transfer of knowledge is no longer attainable for classical-based approaches such as technical education and face-to-face teaching. Tacit knowledge to be transferred which is professional knowledge involves the entire knowledge capital possess by experts. Thus, identifying and codifying tacit knowledge that can improve alumni collaboration is not an easy task (Jnr and $\mathrm{Pa} 2016$ ). Therefore, there is a need to address these aforementioned issues in the university alumni domain (Ermine et al. 2006). Likewise, Yildiz et al. (2014) stated that there is a need for a webbased tool that allows the capturing of tacit knowledge which includes expert recommendations, know-how, as well as explicit knowledge which comprises of documents, reports which can be employed in improving teamwork. 
Academicians such as Davenport and Prusak (1998) pointed out that a knowledge mapping-based tool should provide indexes to tacit knowledge, which may be linked to knowledge yellow pages, actual map, or a skillfully created database. Hence, the knowledge mapping-based system should be seen as a guide like yellow pages that provides where alumni can find knowledge and resources (Cheng et al. 2009). Moreover, Liu and Cui (2017) argued that existing knowledge mapping systems should present the relationship within tacit knowledge navigation, sharing, and inventory for institutions to identify and discover tacit knowledge. In addition, it is required for knowledge management systems to support universities to identify tacit knowledge and manage such knowledge in order to articulate proper knowledge approach to help alumni members identify, develop, share, and assess the knowledge to make informed decisions (Moradi and Mirian 2014). Thus, it is evident that the knowledge system in universities is used not only for presenting what knowledge is relevant to alumni but also for guiding alumni members to locate required knowledge. Accordingly, these systems should enable the sources, displays, flows, constraints, sharing, and reuse of explicit and tacit knowledge within the system (Liu and Ge 2013). The system should be a navigation aid to both explicit and tacit knowledge, showing the important information and the connections between knowledge stores and the dynamics (Sumathy and Chidambaram 2014).

Thus, knowledge mapping facilitates the process of describing knowledge that exists, who possesses specific type of tacit knowledge, where the knowledge expert is positioned, which areas are interrelated and so on. Although, few studies in Table 1 employed knowledge management approaches to support, improving, sharing, and incorporating of university alumni knowledge. Existing approaches inadequately integrate tacit knowledge to provide unified explicit knowledge. Therefore, there is a need for an approach that provides a platform to utilize and share tacit and explicit knowledge to achieve alumni collaboration (Moradi et al. 2012). Therefore, this study employed knowledge mapping to convert tacit knowledge into explicit knowledge to clearly present tacit knowledge in texts, classifications, and graphics to alumni members. Moreover, since knowledge mapping is an approach of knowledge expression and a technique of knowledge storage, this study applies the information flow analysis to design mapping of tacit to explicit knowledge that can be easily be understood by alumni members. In this regard, knowledge mapping is employed to help exploit tacit knowledge to be shared with alumni in order to achieve a more effective and rapid communications of alumni members.

\section{Methodology}

This section aims to provide answer to the first research question; how knowledge mapping system using information flow analysis can be developed to enhance management of university alumni collaboration? Respectively, a knowledge mapping alumni collaborative model is designed to highlight how knowledge mapping system using information flow analysis aid university alumni collaboration as seen in Fig. 5.

Thus, Fig. 5 shows the designed knowledge mapping model. The knowledge mapping model helps to implement the knowledge mapping-based system for 


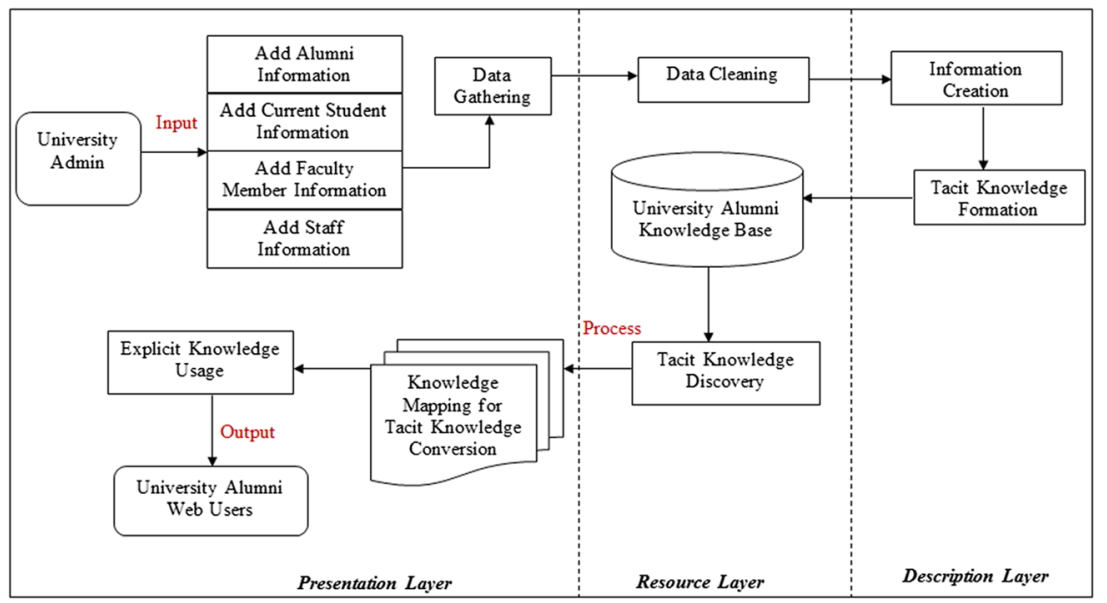

Fig. 5 Designed knowledge mapping model

alumni collaboration as seen in Fig. 10 to maintain the dynamics of the university information by storing knowledge in the university alumni knowledge base to be later used by alumni users. The knowledge can be retrieved by an alumni user by querying keyword search from the knowledge base to be used to facilitate alumni collaboration. In addition, the model helps in building collaborative relationships by matching associated rule-based knowledge to build a knowledge map deployed to facilitate alumni user browse stored information. Congruently, the developed knowledge mapping model is employed to implement the knowledge mappingbased system (see Fig. 10) to facilitate university alumni collaboration.

\section{Description of Model Components}

Figure 5 shows the knowledge mapping model. The model components are described below.

\section{Data Gathering and Data Cleaning}

The component involves the gathering, cleaning, and entering of alumni data into the alumni knowledge base. This component also refines alumni, staffs, students, and faculty members' data to reduce data redundancy in alumni knowledgebase.

\section{Information Creation}

In this component the collected data are stored in tables in the alumni knowledgebase as structured information that has meaning and are basically related to the alumni collaboration. Therefore, these formatted data are saved in the tables representing structured alumni information which is required by alumni, staffs, students, and faculty members for collaboration. 


\section{Tacit Knowledge Formation}

This component entails the storing of collected information of alumni, staffs, students, and faculty members tacit knowledge into the alumni knowledge base.

\section{Tacit Knowledge Discovery}

This component comprises the discovery of the stored alumni tacit knowledge by various alumni members. This step can be performed by deploying knowledge mapping technique as shown in Fig. 6.

\section{Explicit Knowledge Usage}

This component provides alumni-related explicit knowledge which may differ according to the needs of alumni, staffs, students, and faculty members. Moreover, added information that supports alumni collaborative decision-making are utilized in this component.

\section{University Alumni Knowledgebase}

This component is the institutional database that contains all the tacit knowledge of all registered alumni members, current students, staffs, and faculty members in the university. The knowledgebase also contains other information that facilitates collaboration.

\section{University Admin and Alumni Web Users}

This component comprises the university admin that confirm alumni members, current students, staffs, and faculty members in the university. Conversely, the university admin also carries out other administrative operation, whereas the alumni web users comprises the alumni members, current students, staffs, and faculty members' that uses the alumni system for online information search and knowledge-intensive activities. Furthermore,

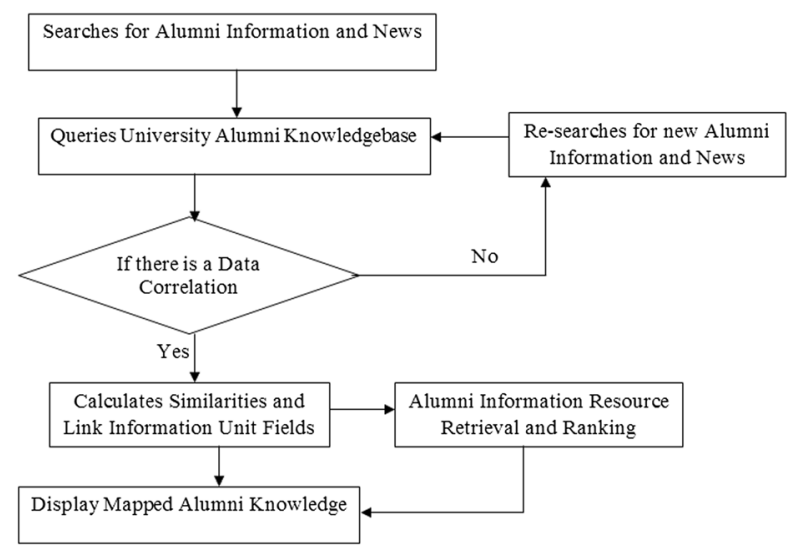

Fig. 6 Designed knowledge mapping flow chart 
the university admin inputs or add alumni-related information, whereas knowledge mapping process uses information flow analysis to provide output to alumni web users.

\section{Developed Knowledge Mapping Model Layers}

The knowledge mapping model is deployed based on three layers which comprises of presentation layer, resource layer, and description layer as seen in Fig. 5 to make the model more flexible and adaptable to the needs of different alumni users in the university. Thus, based on the three layers structure, a change in one will affect other layers in the model.

\section{Presentation Layer}

The presentation layer provides alumni user interfaces and also offers web access to various system functions. This layer comprises of Hyper Text Markup Language (HTML) and Hypertext Preprocessor (PHP) similar to prior studies (Abel 2015; Jnr et al., 2019) which are deployed to implement the user interfaces. The presentation layer also provides visualization functions and capabilities that are personalized in the system to offer dynamic end-user eccentric interactive experience to admin user and student, staff, and faculty member.

\section{Resource Layer}

The resource layer stores data extracted from the alumni members personal documents. These data are parsed, structured, and then stored in the university alumni knowledgebase. Moreover, this layer is controlled in the system using MySQL query, based on Structured Query Language (SQL) statement used in establishing connection with PHP in facilitating alumni collaboration.

\section{Description Layer}

The description layer stores multiple procedures for processing alumni user queries or accessing dissimilar functions. This layer serves as a bridge connecting the presentation (admin user and student, staff, and faculty member front end) layer and the resource layer. In addition, this layer contains modules for different database search and response deployed. Besides, knowledge mapping technique improves the search response time by generating and storing pre-searched result queries.

\section{Information Flow Analysis for Knowledge Mapping Process}

The subsection discusses how information flow analysis is integrated to aid knowledge mapping deployed in the developed model as seen in Fig. 5. Accordingly, the information flow analysis algorithmic procedure is presented in Fig. 6 which shows the information flow analysis operations deployed by knowledge mapping technique. Furthermore, as seen in Fig. 6, information is disseminated to alumni users through mapping knowledge from university alumni knowledgebase, accessed via keyword searches that is matched with the data parameters in the knowledge base tables which 
provides collaborative support to build knowledge links based on knowledge. Additionally, in Fig. 6 the alumni user enters search query as keyword, knowledge mapping mines the university knowledge base and carryout similarity check, and then displays similar searched keywords by ranking the outputs.

Besides, Fig. 6 shows how knowledge mapping encompasses approach, procedures and algorithms, deployed to support students, staffs, alumni, and faculty members in their search and analysis of stored knowledge, thereby illuminating focal topics, essential subdomains, principal knowledge creators, or emerging trends to university alumni members.

Similarly, information flow analysis is particularly significant in a fast growing institutional domain such as universities where new knowledge is created at a fasttracking pace. In such domains, it is important to design and utilize approaches to support required utilization, learning, and analysis by filtering through huge amounts of information and providing comprehensive, holistic, descriptions of the overall knowledge as such information flow analysis a sub technique of knowledge mapping is needed to be employed. Thus, Fig. 7 shows how deployed information flow analysis procedure is applied to presents explicit knowledge to alumni users toward accessing tacit knowledge. The red numbers $(1,2,3 a, 3 b, 4,5,6,7,8$, and 9) show the stages of the deployed information flow analysis procedure. As seen in Fig. 7, information flow analysis allows detailed analyses and comprehensive understanding of the overall alumni knowledge development and current knowledge status.

Moreover, information flow analysis requires the exploration of alumni information and deployment of information provided by the alumni. By analyzing this information and exploring their relationships, alumni members can gain inclusive understanding of the overall recent development that is important to them thereby managing knowledge. Next, Fig. 8 shows the knowledge mapping (information flow analysis) alumni collaboration classification for the proposed knowledge mapping-based system. Also, Fig. 8 further depicts each of the classification in the system where information is

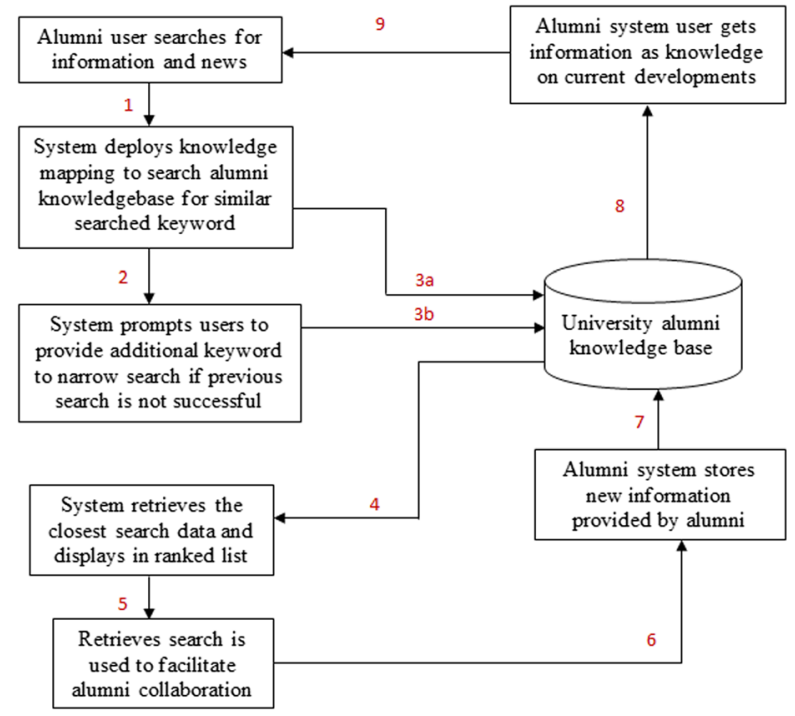

Fig. 7 Deployed information flow analysis procedure 


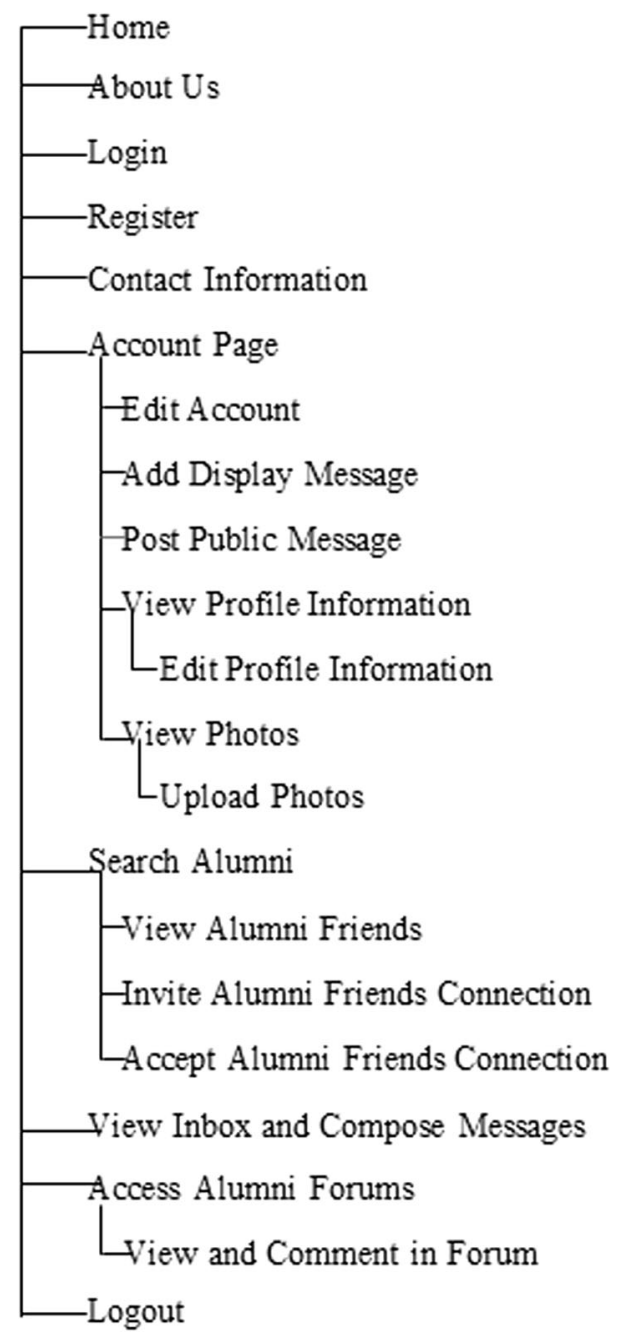

Fig. 8 Knowledge mapping alumni collaboration classification

collected from and saved to the university alumni knowledge base. Similarly, Fig. 9 highlights knowledge mapping alumni collaboration dimensions for the knowledge mapping-based system highlighting all the system modules and how they are interconnected.

Figure 9 depicts how each of the modules are mapped to each other and how information is linked to each sub module using knowledge mapping information flow analysis. It can also be seen from Fig. 9 that the alumni knowledge mapping comprises of information mined from alumni administrator, alumni member, current student, faculty members, and staff members.

Lastly, a few interfaces of the developed knowledge mapping-based system are presented as shown in Figs. 10 and 11 displaying the home, alumni, and message pages. 


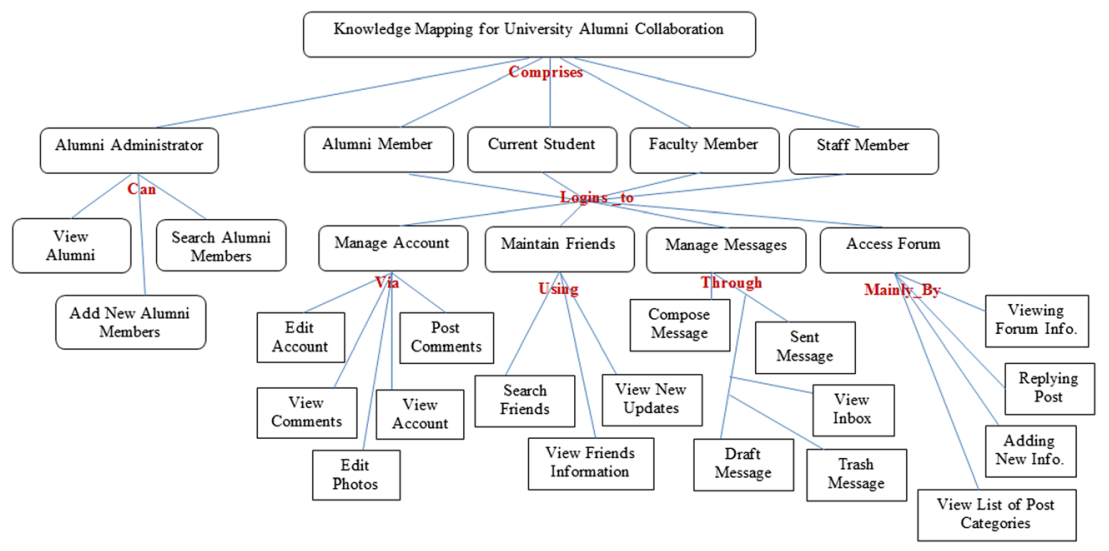

Fig. 9 Knowledge mapping-information flow alumni collaboration dimensions

\section{System Evaluation}

This section aims to provide the answer to the second research question; how to evaluate the developed knowledge mapping alumni collaborative system? Hence, in this study the developed knowledge mapping alumni collaborative system is evaluated using data from the questionnaire.

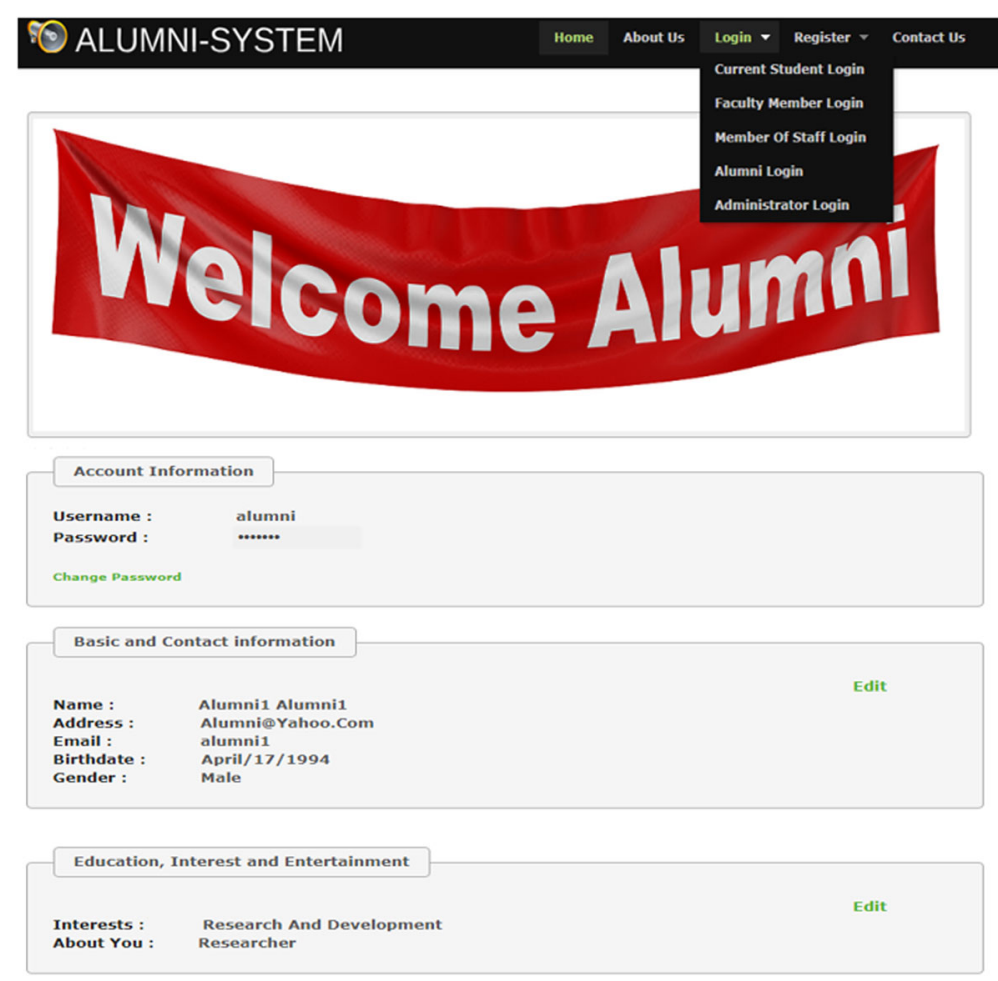

Fig. 10 Developed knowledge mapping-based system (home and alumni page) 


\section{(0) ALUMNI-SYSTEM Home My Page - Friends Messages Forums}

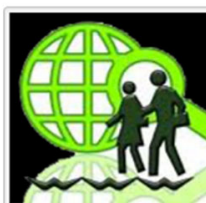

Alumni1 Alumni1

Nov 01, 2018 Login as Alumni

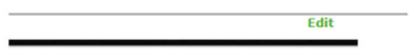

Welcome Alumni to Second Semester 2018...

Alumni1 Alumni1 + Logout
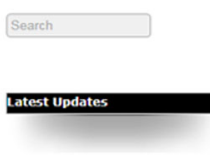

Ei] Salve Mae Dahay chanoed

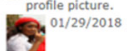

D Samuel Samuel changed profile Q9: ${ }^{09 / 03 / 2012}$

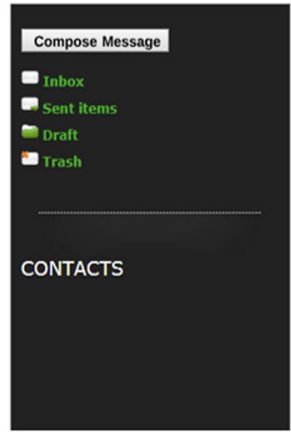

Fig. 11 Developed knowledge mapping-based system (alumni message page)

\section{Data Collection and Analysis Procedure}

The questionnaire was designed to test for the applicability of the developed knowledge mapping-based system (see Figs. 10 and 11). Therefore, the questionnaire instrument was designed based on previous research studies on system evaluation. The instrument questions are divided into two sections; section one consists of demographic characteristics of the respondents which used ordinal measurement. Whereas the second part comprises of questions used to measure the applicability of the developed knowledge mapping-based system using a Likert scale with five response categories (1-5) was used where " 1 " indicates completely disagree, " 3 " is neutral, and " 5 " represents the completely agree. The higher the selected value, the more important the respondent agrees in relation to acceptance of the knowledge mapping-based system.

The respondents were asked to rate how they agree with the items used to measure the developed system in regard to university alumni collaboration. Before administering the questionnaire to purposively selected respondents, experts in information system domain assessed the face and content validity of the questions which lead to the refinement of a few questions based on the feedback from the experts similar to Dang et al. (2011). The data to validate the developed system was collected using paper-based questionnaire conducted in a Malaysian university from the 4th of December 2017 to the 21 st of December 2017. The participants were given a short introduction on the need for the developed system after which they were asked to evaluate the system (see Fig. 10). At the end of the data collection session, a total of 68 
anonymous completed responses were received from the alumni that graduated from Malaysian universities, which is low but higher than samples employed by Sabri et al. (2017), where the author employed 22 samples to validate the implemented alumni system. Next, SPSS was deployed to analyze the collected data in evaluating the applicability of the developed system by carrying out descriptive and exploratory factor analysis.

\section{Results}

In reporting the results from the data collection, the author proceeds in several steps by reporting on the demographic data, normality, reliability, validity, descriptive statistics, and exploratory factor analysis. Accordingly, Table 2 shows the demographic characteristic of the questionnaire respondents. Table 2 shows the gender of the respondents where more males participated in the survey, and the majority was between the age distribution of 25-34. Also, the respondents are mostly master's holders enrolled as postgraduate (program category) mainly from engineering and computing. Lastly, the respondents involved in the study are alumni with working experience of 0-5 years,

Table 2 Characteristic of the questionnaire respondents

\begin{tabular}{|c|c|c|c|}
\hline Demographic Profile & Options & Frequency & Percentage \\
\hline \multirow[t]{2}{*}{ Gender } & Male & 56 & $82.4 \%$ \\
\hline & Female & 12 & $17.6 \%$ \\
\hline \multirow[t]{3}{*}{ Age } & Below 25 & 27 & $40.2 \%$ \\
\hline & $25-34$ & 30 & $43.1 \%$ \\
\hline & $35-44$ & 11 & $16.7 \%$ \\
\hline \multirow[t]{4}{*}{ Education Qualification } & Diploma & 5 & $7.8 \%$ \\
\hline & Bachelor's degree & 27 & $39.2 \%$ \\
\hline & Master's degree & 29 & $43.1 \%$ \\
\hline & $\mathrm{PhD}$ & 7 & $9.8 \%$ \\
\hline \multirow[t]{4}{*}{ Program Category } & Postgraduate & 37 & $54.9 \%$ \\
\hline & Degree & 23 & $34.3 \%$ \\
\hline & Diploma & 2 & $2.9 \%$ \\
\hline & Foundation & 6 & $7.8 \%$ \\
\hline \multirow[t]{5}{*}{ Faculty } & Account and business management & 6 & $8.8 \%$ \\
\hline & Professional accounting & 17 & $24.5 \%$ \\
\hline & English & 6 & $8.8 \%$ \\
\hline & Hospitality and tourism & 6 & $8.8 \%$ \\
\hline & Engineering and computing & 33 & $49.0 \%$ \\
\hline \multirow[t]{5}{*}{ Experience } & $0-5$ & 40 & $58.8 \%$ \\
\hline & $6-10$ & 15 & $21.6 \%$ \\
\hline & $11-15$ & 7 & $10.8 \%$ \\
\hline & $16-20$ & 4 & $5.9 \%$ \\
\hline & $>20$ & 2 & $2.9 \%$ \\
\hline
\end{tabular}


highlighting that they are new graduates, where experience signifies the number of years of working after graduation from the studied Malaysian university.

In addition, Table 3 depicts the questionnaire item employed to test the applicability of the developed knowledge mapping-based system. Each of the questionnaire items are derived from prior studies (see Table 3 ) on the validation of implemented information systems.

\section{Normality, Reliability, and Validity Analysis}

The questionnaire data is subjected to the test of normality to ascertain if the reply from the respondents is normally distributed or not (Hair et al. 2006). In this study, skewness and kurtosis are employed to determine the normality of the items. Thus, the kurtosis and skewness values between \pm 2 are considered effective as recommended by George

Table 3 Questionnaire items

\# Items $\quad$ Sources

1 Usability of the system in providing knowledge adaptation

2 Effectiveness of the system in sharing knowledge to alumni members

3 Acceptance of the system in promoting collaboration among alumni members

4 User perceived usefulness and efficiency of the system

5 Sufficiency of the system for knowledge transfer among alumni members

6 Sufficiency for knowledge retaining to provide alumni collaboration

7 Sufficiency for facilitating knowledge reuse among alumni members

8 Sufficiency for knowledge gathering from several alumni members

9 Capability of the system in providing information to facilitate alumni communication

10 Efficient and consistent of the system to be utilized in real use

11 Fitness of the of the system to improve knowledge discovery for alumni members

12 Information searching capability of the system

13 User satisfaction on information provided by the system

14 Simplicity of information presented by the system to alumni members

15 Comprehensibility of information retrieved by the system to alumni members.

16 Overall benefits of the system to alumni members

17 Adequacy of information provided by the system to alumni members
(O’Keefe and O'Leary 1993; Curet et al. 1996)

(O’Keefe and O'Leary 1993; Dang et al. 2011)

(Curet et al. 1996; Sabri et al. 2017; Jnr et al. 2019)

(Dang et al. 2011; Anthony et al. 2018)

(Jafari et al. 2009; Jnr and Pa 2016)

(Jafari et al. 2009; Jnr and Pa 2016)

(Jafari et al. 2009; Jnr and Pa 2016)

(Jafari et al. 2009; Jnr and Pa 2016)

(Jafari et al. 2009; Jnr and Pa 2016)

(Heide and Lis 2012; Anthony et al. 2018)

(Jnr and Pa 2016; Sabri et al. 2017)

(Jafari et al. 2009; Anthony et al. 2018)

(Butler et al. 2001; Calitz et al. 2017)

(Sabri et al. 2017; Anthony Jr et al. 2018)

(Anthony et al. 2018; Anthony Jr et al. 2018)

(Sabri et al. 2017; Anthony et al. 2018)

(Jnr and Pa 2016; Anthony et al. 2018) 
and Mallery (2005). The detailed analysis of the data normality assessment depicted in Table 4 indicates that there were no values exceeding the acceptable range of skewness as suggested by George and Mallery (2005) which is between -2 and +2 . However, for kurtosis results from Table 4 suggest that item 2 is given as 3.141 and item 5 is given

Table 4 Results of normality, reliability, and validity analysis

\begin{tabular}{|c|c|c|c|c|c|c|}
\hline \multirow[t]{2}{*}{ \# } & \multirow[t]{2}{*}{ Items } & \multicolumn{2}{|l|}{ Normality } & \multirow{2}{*}{$\begin{array}{l}\text { Reliability } \\
\text { Cronbach's } \\
\text { alpha }(\alpha)\end{array}$} & \multirow{2}{*}{$\begin{array}{l}\text { Convergent } \\
\text { Validity } \\
\text { (r) }\end{array}$} & \multirow{2}{*}{$\begin{array}{l}\text { Discriminate } \\
\text { Validity } \\
\left(\mathrm{r}^{2}\right)\end{array}$} \\
\hline & & Skewness & Kurtosis & & & \\
\hline 1 & $\begin{array}{l}\text { Usability of the system in providing } \\
\text { knowledge adaptation }\end{array}$ & -0.788 & -0.430 & 0.758 & 0.304 & 0.387 \\
\hline 2 & $\begin{array}{l}\text { Effectiveness of the system in sharing } \\
\text { knowledge to alumni members }\end{array}$ & -1.401 & 3.141 & 0.739 & 0.529 & 0.544 \\
\hline 3 & $\begin{array}{l}\text { Acceptance of the system in promoting } \\
\text { collaboration among alumni } \\
\text { members }\end{array}$ & -1.486 & 1.323 & 0.777 & 0.019 & 0.524 \\
\hline 4 & $\begin{array}{l}\text { User perceived usefulness and } \\
\text { efficiency of the system }\end{array}$ & -1.486 & 1.788 & 0.731 & 0.577 & 0.731 \\
\hline 5 & $\begin{array}{l}\text { Sufficiency of the system for } \\
\text { knowledge transfer among alumni } \\
\text { members }\end{array}$ & -1.075 & 0.966 & 0.733 & 0.566 & 0.617 \\
\hline 6 & $\begin{array}{l}\text { Sufficiency for knowledge retaining to } \\
\text { provide alumni collaboration }\end{array}$ & -1.960 & 5.822 & 0.739 & 0.507 & 0.691 \\
\hline 7 & $\begin{array}{l}\text { Sufficiency for facilitating knowledge } \\
\text { reuse among alumni members }\end{array}$ & -1.480 & 1.295 & 0.756 & 0.333 & 0.542 \\
\hline 8 & $\begin{array}{l}\text { Sufficiency for knowledge gathering } \\
\text { from several alumni members }\end{array}$ & -1.206 & 0.505 & 0.746 & 0.467 & 0.548 \\
\hline 9 & $\begin{array}{l}\text { Capability of the system in providing } \\
\text { information to facilitate alumni } \\
\text { communication }\end{array}$ & -0.883 & -0.261 & 0.753 & 0.369 & 0.596 \\
\hline 10 & $\begin{array}{l}\text { Efficient and consistent of the system } \\
\text { to be utilized in real use }\end{array}$ & -0.558 & -0.653 & 0.751 & 0.391 & 0.555 \\
\hline 11 & $\begin{array}{l}\text { Fitness of the of the system to improve } \\
\text { knowledge discovery among alumni } \\
\text { members }\end{array}$ & -1.059 & 0.152 & 0.754 & 0.358 & 0.350 \\
\hline 12 & $\begin{array}{l}\text { Information searching capability of the } \\
\text { system }\end{array}$ & -0.561 & -0.742 & 0.763 & 0.229 & 0.327 \\
\hline 13 & $\begin{array}{l}\text { User satisfaction on information } \\
\text { provided by the system }\end{array}$ & -0.240 & -1.981 & 0.767 & 0.156 & 0.500 \\
\hline 14 & $\begin{array}{l}\text { Simplicity of information presented by } \\
\text { the system to alumni members }\end{array}$ & -0.464 & -1.007 & 0.754 & 0.356 & 0.420 \\
\hline 15 & $\begin{array}{l}\text { Comprehensibility of information } \\
\text { retrieved by the system to alumni } \\
\text { members. }\end{array}$ & -0.601 & -0.696 & 0.752 & 0.377 & 0.453 \\
\hline 16 & $\begin{array}{l}\text { Overall benefits of the system to } \\
\text { alumni members }\end{array}$ & -0.580 & -1.698 & 0.772 & 0.069 & 0.487 \\
\hline 17 & $\begin{array}{l}\text { Adequacy of information provided by } \\
\text { the system to alumni members }\end{array}$ & -0.966 & -0.231 & 0.767 & 0.204 & 0.358 \\
\hline
\end{tabular}


5.822 which show that the responses from both items do not meet the kurtosis benchmark and as such are not normally distributed, but all other 15 questionnaire items are normally distributed.

Moreover, Table 4 presents the reliability or internal consistency of the questionnaire items, where Anthony et al. (2020) defined reliability as the range in which the questionnaire instrument presents the same result consistently. The value of Cronbach's alpha $(\alpha)$ is employed to measure the reliability of the questionnaire items. Hair et al. (2006) suggested that the Cronbach's alpha higher than 0.7 based on the scale where $>$ $0.9=$ excellent,$>0.8=$ good, $>0.7=$ acceptable, $>0.6=$ questionable, $>0.5=$ poor, and $<0.5=$ unacceptable. Therefore, the closer Cronbach's alpha coefficient is to 1.0 the greater the reliability of the questionnaire items. Hence, results from Table 4 indicate that the individual Cronbach's alpha value of each questionnaire items is greater than 0.7 benchmark showing an acceptable reliability value for the questionnaire items.

Likewise, the validity is assessed, where the validity refers to the degree in which measurement instrument rationally measure what it intended to evaluate. In this study, the validity is checked by considering the convergent validity and discriminate validity. The convergent validity is measured based on the Pearson correlation coefficient $(r)$, whereas the discriminate validity is measured based on $r^{2}$ that is employed based on the recommendations of Jnr et al. (2019) where the strength of correlation coefficient ranges from 0.1 to $0.29 \mathrm{OR}-0.1$ to -0.29 as weak, 0.30 to $0.49 \mathrm{OR}-0.30$ to -0.49 as moderate and 0.50 to $1.0 \mathrm{OR}-0.50$ to -1.0 as strong. Likewise, Fields (2009) mentioned that the Pearson correlation coefficient $(r$ ) (must be between -1 to +1 ). Accordingly, results from Table 4 suggest that the Pearson's correlation $(r)$ value was between the values of 0.3 and 0.9 representing a medium and strong, positive correlation, signifying that the questionnaire items are statistically significant at $p=0.000$. Thus, confirming the validity of all other questionnaire items, apart from item 3 with $(r=0.019)$ and item 16 with $(r=0.069)$ which are below the 0.1 benchmark signifying that the responses from the respondents of both items do not correlate with the other 15 questionnaire items.

\section{Descriptive Data Analysis}

Descriptive statistic is used to describe the data collected in research studies and to accurately characterize the items under observation within a specific sample. In this research, the mean and standard deviation (SD) score is utilized to examine the importance of each item used to measure the applicability of the knowledge mapping-based system, similar to Cheng and Humphreys (2012); Jnr et al. (2019). Since this study employed 5 point Likert scale, all questionnaire item mean values should be higher than 2.5 as suggested by Anthony Jr et al. (2018) based on the mean benchmark where 0.00-2.49 is low, 2.50-3.49 is moderate, 3.50-5.00 is high. Similarly, it is advisable for the standard deviation values to be lower than 1 implicating that replies from the respondents are close and not extensively distributed as suggested by Anthony et al. (2020).

Results from Table 5 reveal that each item overall mean is above 4.00 at a scale of 5 , where item 3 which measure the acceptance of the developed system in promoting collaboration has the highest mean of 4.70 , and the standard deviation of each item is 
Table 5 Results of descriptive analysis

\begin{tabular}{|c|c|c|c|c|c|}
\hline \# & Items & Min & Max & Mean & $\mathrm{SD}$ \\
\hline 1 & Usability of the system in providing knowledge adaptation & 3 & 5 & 4.45 & 0.654 \\
\hline 2 & Effectiveness of the system in sharing knowledge to alumni members & 2 & 5 & 4.51 & 0.625 \\
\hline 3 & Acceptance of the system in promoting collaboration among alumni members & 3 & 5 & 4.70 & 0.523 \\
\hline 4 & User perceived usefulness and efficiency of the system & 2 & 5 & 4.45 & 0.791 \\
\hline 5 & Sufficiency of the system for knowledge transfer among alumni members & 2 & 5 & 4.39 & 0.720 \\
\hline 6 & Sufficiency for knowledge retaining to provide alumni collaboration & 1 & 5 & 4.43 & 0.777 \\
\hline 7 & Sufficiency for facilitating knowledge reuse among alumni members & 3 & 5 & 4.68 & 0.548 \\
\hline 8 & Sufficiency for knowledge gathering from several alumni members & 3 & 5 & 4.63 & 0.561 \\
\hline 9 & $\begin{array}{l}\text { Capability of the system in providing information to facilitate alumni } \\
\text { communication }\end{array}$ & 3 & 5 & 4.49 & 0.641 \\
\hline 10 & Efficient and consistent of the system to be utilized in real use & 3 & 5 & 4.48 & 0.576 \\
\hline 11 & $\begin{array}{l}\text { Fitness of the of the system to improve knowledge discovery } \\
\text { among alumni members }\end{array}$ & 3 & 5 & 4.60 & 0.567 \\
\hline 12 & Information searching capability of the system & 3 & 5 & 4.51 & 0.558 \\
\hline 13 & User satisfaction on information provided by the system & 4 & 5 & 4.56 & 0.499 \\
\hline 14 & Simplicity of information presented by the system to alumni members & 3 & 5 & 4.52 & 0.540 \\
\hline 15 & $\begin{array}{l}\text { Comprehensibility of information retrieved by the system to } \\
\text { alumni members. }\end{array}$ & 3 & 5 & 4.52 & 0.558 \\
\hline 16 & Overall benefits of the system to alumni members & 4 & 5 & 4.64 & 0.483 \\
\hline 17 & Adequacy of information provided by the system to alumni members & 3 & 5 & 4.49 & 0.671 \\
\hline
\end{tabular}

low showing that the values do not deviate far from value " 1 ". This implicates that there is a common agreement in relation to the perception of respondents in relation to the importance of the questionnaire items. Accordingly, results from Table 5 suggest that the respondents perceive that the knowledge mapping-based system is applicable in providing knowledge to foster alumni collaboration.

Furthermore, based on the results from Table 5, the developed system is confirmed to be affected based on the high mean value and reduced standard deviation value. In summary, results from the survey questionnaire data indicate that the developed system is applicable in providing information and facilitating university alumni collaboration. Lastly, Table 5 shows the maximum and minimum values for selected by each respondent which ranges from 1 to 4 for minimum value and 5 for maximum value selected by the respondents.

\section{Exploratory Factor Analysis}

Exploratory factor analysis (EFA) is a statistical technique utilized to identify the relationship between the questionnaire item and respondents replies. EFA is based on the common factor model (Fields 2009). EFA is adopted when there are no hypotheses about the measured items. The criteria for practical and statistical significance of factor loading or communalities can be classified based on their magnitude (Greater than + $0.30=$ minimum consideration level, $+0.40=$ more important and $+0.50=$ practically 
Table 6 Results of exploratory factor analysis

\begin{tabular}{|c|c|c|c|c|}
\hline \# & Items & Loading & $\begin{array}{l}\text { Total } \\
\text { Variance }\end{array}$ & $\begin{array}{l}\% \text { of } \\
\text { Variance }\end{array}$ \\
\hline 1 & Usability of the system in providing knowledge adaptation & 0.616 & 3.904 & 22.964 \\
\hline 2 & $\begin{array}{l}\text { Effectiveness of the system in sharing knowledge to } \\
\text { alumni members }\end{array}$ & 0.699 & 1.997 & 11.748 \\
\hline 3 & $\begin{array}{l}\text { Acceptance of the system in promoting collaboration among } \\
\text { alumni members }\end{array}$ & 0.831 & 1.869 & 10.997 \\
\hline 4 & User perceived usefulness and efficiency of the system & 0.794 & 1.538 & 9.048 \\
\hline 5 & $\begin{array}{l}\text { Sufficiency of the system for knowledge transfer among } \\
\text { alumni members }\end{array}$ & 0.779 & 1.165 & 6.853 \\
\hline 6 & Sufficiency for knowledge retaining to provide alumni collaboration & 0.717 & 1.047 & 6.156 \\
\hline 7 & Sufficiency for facilitating knowledge reuse among alumni members & 0.823 & 1.030 & 6.061 \\
\hline 8 & Sufficiency for knowledge gathering from several alumni members & 0.806 & 0.851 & 5.004 \\
\hline 9 & $\begin{array}{l}\text { Capability of the system in providing information to facilitate } \\
\text { alumni communication }\end{array}$ & 0.763 & 0.735 & 4.324 \\
\hline 10 & Efficient and consistent of the system to be utilized in real use & 0.773 & 0.649 & 3.816 \\
\hline 11 & $\begin{array}{l}\text { Fitness of the of the system to improve knowledge discovery among } \\
\text { alumni members }\end{array}$ & 0.645 & 0.527 & 3.100 \\
\hline 12 & Information searching capability of the system & 0.739 & 0.502 & 2.953 \\
\hline 13 & User satisfaction on information provided by the system & 0.839 & 0.389 & 2.290 \\
\hline 14 & Simplicity of information presented by the system to alumni members & 0.722 & 0.248 & 1.460 \\
\hline 15 & $\begin{array}{l}\text { Comprehensibility of information retrieved by the system } \\
\text { to alumni members. }\end{array}$ & 0.675 & 0.228 & 1.343 \\
\hline 16 & Overall benefits of the system to alumni members & 0.763 & 0.191 & 1.122 \\
\hline 17 & Adequacy of information provided by the system to alumni members & 0.580 & 0.129 & 0.760 \\
\hline
\end{tabular}

significant) (Hair et al. 2006). Therefore, the questionnaire items were subjected to EFA to ascertain the underlying items that influences respondents' acceptance toward the knowledge mapping-based system. In addition, EFA helps to explain the item that best confirms the system in relation to the applicability criteria of all questionnaire items. Hence, the items, factor loadings, total, and percentage of variance that best describe the applicability criteria of the knowledge mapping alumni collaborative system are presented in Table 6.

Table 6 shows the results for EFA, where the factor loading of each item indicates a level that should be significantly greater than 0.50 , as recommended by to Hair et al. (2006). Therefore, results from Table 6 suggest that the all items loading are acceptable. Furthermore, the total variance of all items is greater than 0.1 , as recommended by Straub et al. (2004); Anthony et al. (2018).

In addition, item 1 which rates the usability in knowledge adaptation has the highest percentage of variance with a value of 22.964 explaining (22.964\%) of the variance and satisfaction of the knowledge mapping-based system, and item 17 which rates the adequacy of information provided has the lowest with a value of 0.760 explaining $(0.76 \%)$ of acceptance variance of the developed system. 
Figure 12 shows the Eigen values of the questionnaire items suggesting that item 1 has an Eigen value of 3.904 and item 17 has the lowest Eigen value of 0.129. The results from the Eigen value also reveal that more than half of the items Eigen value are equal to 1 . Hence, the developed knowledge mapping-based system is applicable in providing knowledge to support alumni collaboration. Besides, the relationships of the measured factors for the system performance and acceptability are determined by the orthogonal factor rotation with varimax rotation based on the Kaiser-Meyer-Olkin (KMO) measure, Bartlett's test (BT) of sphericity factors extraction, degree of freedom (DF), and significant value ( $p$ value) which should be $<0.05$. Correspondingly, KMO value ranges from 0 to 1 . Statistically, KMO values of more than 0.5 and 0.7 can be considered average and good (Anthony et al. 2020).

Note $p$ value is significant when $\mathrm{P}=<0.05$ using two-tail test

Results from Table 7 reveal that the KMO value of all factors is given as 0.550 , which is much higher than the acceptable threshold of 0.50 . The results further suggest that the value of the test statistic for Bartlett's sphericity chi-square value is large with value 607.137 , DF of 136 , and $p$ value $<0.05$. Thus, based on the KMO and the Barlett's test of sphericity values and significant value, it can be concluded that the knowledge mapping-based system was accepted by the respondents.

\section{Discussion}

This study integrated knowledge mapping as a technique to facilitate university alumni collaboration to assist in locating, retrieving, and displaying of alumni information to the system users. Respectively, knowledge mapping is integrated as a knowledge management technique to effectively visualize the sources, flows, constraints, and terminations of tacit and explicit knowledge by improving the understanding of relationships between knowledge stores and dynamics for alumni collaboration. According to Yun et al. (2011), knowledge mapping is used to develop conceptual maps as hierarchies or nets, support knowledge scripting and profiling, and provide highly developed procedures to elicit and

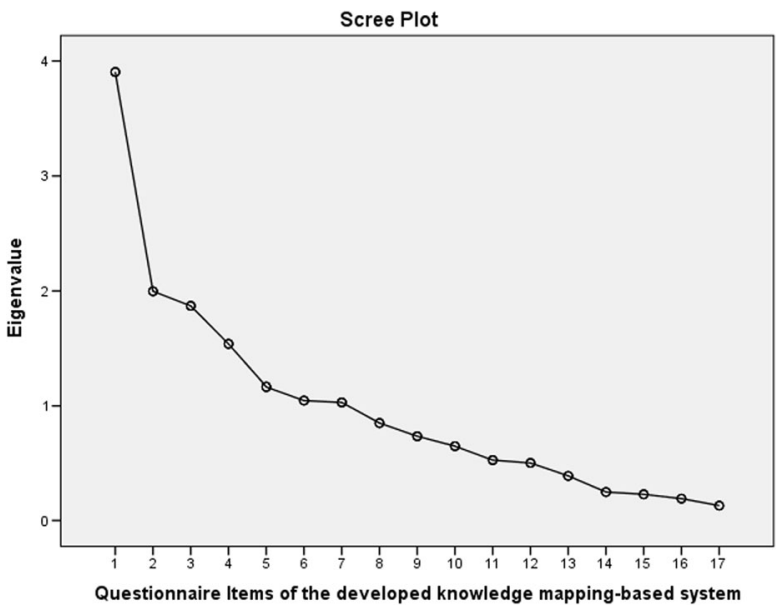

Fig. 12 Scree plot of the Eigen values of the items 
Table 7 Results of KMO and Bartlett's tests

Kaiser-Meyer-Olkin Measure of Sampling Adequacy.

0.550

Bartlett's Test of Sphericity

Approx. Chi-Square

607.137

df

136

Sig.

0.000

document conceptual maps from various knowledge alumni in the system. In addition, Heide and Lis (2012) argued that knowledge mapping can help capitalize knowledge for projects and organizations by acting as a set of processes which identify and visualize the resources and flows of knowledge in the alumni system. Therefore, knowledge map shows relations among procedures, concepts, and competency and provides easy and effective access to knowledge sources. Knowledge mapping aids in retrieving knowledge that is utilized by alumni members where they share information.

Therefore, findings from this study present the developed knowledge mapping-based system that is evaluated using questionnaire to test the applicability of the system. The collected data was analyzed using SPSS. Several statistical tests such as analysis of demographic data test of normality, reliability test, validity test, descriptive statistical analysis, and exploratory factor analysis were carried out to evaluate the applicability of the system. Results suggest that the knowledge mapping-based system facilitates collaboration among alumni members by providing information through information flow analysis to alumni members in universities. This is confirmed by the mean and SD value ranging from $4.70(0.523)$ to $4.39(0.720)$ for the applicability of the developed system in being usability for knowledge adaptation, effective in sharing knowledge, acceptance by the respondents in promoting collaboration, user perceived that the system is usefulness and efficiency, and lastly sufficiency of the system in transferring knowledge. Furthermore, results from this study confirm that the developed system has acceptable mean and SD value which range from $4.68(0.548)$ to $4.43(0.777)$ for sufficiency of the system in retaining knowledge, facilitating knowledge reuse, and knowledge gathering toward facilitating alumni collaboration which is efficient and consistent in the real use, and lastly the fitness of the system is satisfactory to the alumni members. In addition, results from this study reveal that the developed system has acceptable mean and SD value which range from 4.64(0.483) to 4.51(0.656) in supporting information searching, users being satisfied with the information provided, the simplicity and comprehensibility of information retrieved, and presented being benefits to the users where the information provided is considered adequate to facilitate alumni collaboration in universities.

\section{Implications of Study}

\section{Theoretical Implications}

At the moment, there are available alumni systems that are being utilized by universities to connect with alumni members. However, these available systems do not support students, alumni, staffs, and faculty members to collaborate and communicate effectively. This is due 
to these systems providing inadequate tacit knowledge mapped or codified as explicit knowledge, where knowledge is recognized as an important strategic resource for successful communication and information flow for a specific group of people. Accordingly, this study integrates knowledge mapping as knowledge management technique to optimize the effective and efficient use of the institutional knowledge. Consequently, this research infuses knowledge mapping with information flow analysis to discover vital knowledge within the institution and then provides a procedure that depicts where to find the required knowledge. Theoretically, this paper utilizes knowledge mapping as a technique to visualize the sources and flows of tacit to explicit knowledge in facilitating communication and collaboration. Thus, knowledge mapping using information flow analysis designed a concrete map as hierarchies to support knowledge scripting and profiling of alumni members toward providing a practical approach to elicit information for alumni collaboration.

Furthermore, a knowledge mapping model is designed to serve as an interactive information flow, which defines, organizes, and develops procedural knowledge in order to explore and address communication problems among alumni members. Furthermore, knowledge mapping has been proposed as a technique for the university alumni system to assist in the location, retrieval and display of students, events, and others alumni information to the system users. Theoretically, the designed model helps in managing the communication among the university and its alumni. The model also fosters association among alumni members to keep the alumni members frequently informed about special activities at the university to maintain and promote the global competitiveness of qualifications and degrees at the university. Lastly, the model provides an easy way of processing data such as getting information, communication, and interaction between the school and alumni, to link alumni with their co-alumni, and also provide current student which a means to network with past students.

\section{Practical Implications}

The application of knowledge management has become increasingly practical as more data sources are available through the web. Thus, there is a need for an effective knowledge management technique that can be systematically deployed to locate, retrieve, and present crucial knowledge to facilitate university alumni collaboration. Although, there are alumni approaches proposed by prior studies (see Table 1) that are not better designed for collaboration and knowledge sharing between alumni and their universities. Similarly, only fewer studies integrated knowledge management technique such as knowledge mapping-information flow analysis to provide tacit knowledge to alumni members in fostering collaboration. To address this gap, this study develops a knowledge mapping alumni collaborative system, which offers a methodological and comprehensive procedure to support communication, and provides tacit knowledge to alumni members. Moreover, exiting alumni approaches (Barnard and Rensleigh 2008; Chi et al., 2012; Deros et al. 2012; Jamil and Ahmad 2013; Teixeira and Maccari 2014; Scillitoe 2013; Rattanamethawong et al. 2015; Sabri et al., 2017) provided basic information based on user queries. Guided by the knowledge mapping technique, this study develops a system capable of providing student, alumni, staffs, and faculty member with comprehensive depictions of knowledge in university domain.

Furthermore, as depicted in Figs. 8 and 9, the developed system provides a medium as a community of practice or communities of interests where alumni members can 
share ideas thus creating a collaborative platform for alumni virtually. Practically, the approach proposed in this study provides a robust system for virtualizing and specifying crucial information by connects theory to practice towards achieving a valid, rigorous, and applicable tool. In addition, the system deploys information flow analysis that supports the search and easily comprehensible presentations of alumni data. Overall, results from this study suggest that the developed system employs information flow analysis procedures (see Figs. 4 and 7) to effectively display the retrieved search query in an intuitive and easily understandable approach. Besides, contrary to previous studies that focus on traditional alumni management (see Table 1), the developed knowledge mapping-based system deploys systematic search to support knowledge discovery for alumni members. Thus, findings from this study indicate that the developed system is applicable in providing a holistic and comprehensive knowledge support to alumni members to conveniently accomplish alumni collaboration.

\section{Conclusion, Limitations and Future Works}

This research contributed to the body of knowledge by integrating knowledge mapping and information flow analysis to develop a knowledge mapping-based system. The system was developed by reviewing prior studies on knowledge mapping and university alumni collaboration after which the knowledge mapping model was designed based on information flow analysis procedures. Findings from this study confirm the applicability of the developed system based on the descriptive, reliability, validity, and EFA analyses. The applicability of the developed system was evaluated using questionnaire data collected from respondents in a Malaysian university. Results from this study reveal that the system was considered acceptable by the respondents in being applicable in facilitating information, dissemination, and management among university students, alumni, faculty members, and university staffs.

Furthermore, every research possesses limitations, and this study is not an exception. Hence, knowledge mapping technique is only employed in this study. Empirically, data was collected from respondents in a single Malaysian university. Hence the results from this study cannot be generalized to other universities. Lastly, this study did not examine factors that influence students and alumni in adopting the developed knowledge mapping-based system. Thus, future research will be directed to integrate a hybrid technique by incorporating software agents to knowledge mapping to improve the autonomous capability of the developed system. Moreover, a longitudinal study will be carried out where data is to be collected from students and alumni from several universities to increase sample size. Finally, the factors that influence alumni in adopting the developed system will be a fruitful endeavor for future investigation.

Funding Information Open Access funding provided by NTNU Norwegian University of Science and Technology (incl St. Olavs Hospital - Trondheim University Hospital).

Open Access This article is licensed under a Creative Commons Attribution 4.0 International License, which permits use, sharing, adaptation, distribution and reproduction in any medium or format, as long as you give appropriate credit to the original author(s) and the source, provide a link to the Creative Commons licence, and indicate if changes were made. The images or other third party material in this article are included in the article's Creative Commons licence, unless indicated otherwise in a credit line to the material. If material is not 
included in the article's Creative Commons licence and your intended use is not permitted by statutory regulation or exceeds the permitted use, you will need to obtain permission directly from the copyright holder. To view a copy of this licence, visit http://creativecommons.org/licenses/by/4.0/.

\section{References}

Abel, M. H. (2015). Knowledge map-based web platform to facilitate organizational learning return of experiences. Computers in Human Behavior, 51, 960-966.

Aldieri, L., Kotsemir, M. N., \& Vinci, C. P. (2018). The effects of collaboration on research performance of universities: An analysis by federal district and scientific fields in Russia. Journal of the Knowledge Economy, 1-22.

Altuntaş, S., \& Baykal, Ü. (2017). An analysis of alumni performance: A study of the quality of nursing education. Nurse Education Today, 49, 135-139.

Andrea, H. (2006). Building a Knowledge Map: An Analysis of Five Years of Topics Presented at a KM Community of Practice. OLKC Conference at the University of Warwick, Coventry 20th - 22nd March 2006.

Anthony Jr., B. (2019). A developed software agent-knowledge-assisted procurement management tool for retailing enterprise: A feasibility study. VINE Journal of Information and Knowledge Management Systems, 49(1), 54-75.

Anthony Jr., B., Abdul Majid, M., \& Romli, A. (2018). A collaborative agent based green IS practice assessment tool for environmental sustainability attainment in enterprise data centers. Journal of Enterprise Information Management, 31(5), 771-795.

Anthony, B., Abdul Majid, M., \& Romli, A. (2018). Heterogeneous agent-enabled decision system for evaluating green IT performance in industrial environments. Journal of Decision Systems, 27(1), 37-62.

Anthony, B., Majid, M. A., \& Romli, A. (2020). Green IS diffusion in organizations: A model and empirical results from Malaysia. Environment, Development and Sustainability, 22(1), 383-424.

Aziz, A. A. A., Abdullah, R., \& Ibrahim, H. (2011). A model of knowledge mapping in visualizing the hotspot of dengue. IEEE Conference on Open Systems, 444-449.

Baade, R. A., \& Sundberg, J. O. (1996). What determines alumni generosity? Economics of Education Review, 15(1), 75-81.

Balaid, A. S. S., Zibarzani, M., \& Rozan, M. Z. A. (2013). A comprehensive review of knowledge mapping techniques. Journal of Information Systems Research and Innovation, 3, 61-66.

Banka, S. N. (2019). Influence of alumni association on the Management of Public Universities in the north central states of Nigeria. International Journal of Innovative Education Research, 7(1), 31-41.

Barnard, Z., \& Rensleigh, C. (2008). Investigating online community portals for enhanced alumni networking. The Electronic Library, 26(4), 433-445.

Butler, F., Whitehead, R., and Winkleman, M. (2001). Student, alumni and employer satisfaction to a collaborative learning approach. 31 stAnnual Frontiers in Education Conference. Impact on Engineering and Science Education. Conference Proceedings, 3-9.

Calitz, A. P., Greyling, J. H., \& Glaum, A. (2017). Evaluating alumni satisfaction of an CS/IS department. Magaliesberg: SACLA Conference.

Cheng, M. M., \& Humphreys, K. A. (2012). The differential improvement effects of the strategy map and scorecard perspectives on managers' strategic judgments. The Accounting Review, 87(3), 899-924.

Cheng, Y. T., Chuang, H. M., and Wen, C. C. (2009). A study on applying mind mapping to build a knowledge map of the project risk management of research and development. ICICIC, 30-33. IEEE.

Chi, H., Jones, E. L., \& Grandham, L. P. (2012). Enhancing mentoring between alumni and students via smart alumni system. Procedia Computer Science, 9, 1390-1399.

Curet, O., Jackson, M., \& Tarar, A. (1996). Designing and evaluating a case-based learning and reasoning agent in unstructured decision making. In International conference on systems, man and cybernetics. Information intelligence and systems (pp. 2487-2492).

Dang, Y., Zhang, Y., Hu, P. J. H., Brown, S. A., \& Chen, H. (2011). Knowledge mapping for rapidly evolving domains: A design science approach. Decision Support Systems, 50(2), 415-427.

Davenport, T. H., \& Prusak, L. (1998). Working knowledge: How organizations manage what they know. Harvard Business Press, 1-199. 
Deros, B. M., Mohamed, A., Mohamed, N., \& Ihsan, A. K. A. M. (2012). A study of alumni feedback on outcome based education in the Faculty of Engineering and Built Environment, Universiti Kebangsaan Malaysia. Procedia-Social and Behavioral Sciences, 60, 313-317.

Diamond, W. D., \& Kashyap, R. K. (1997). Extending models of Prosocial behavior to explain University alumni contributions. Journal of Applied Social Psychology, 27(10), 915-928.

Eppler, M. J. (2001). Making knowledge visible through intranet knowledge maps: Concepts, elements, cases. In Proceedings of the 34th annual Hawaii international conference on system sciences (pp. 9-15).

Ermine, J. L., Boughzala, I., \& Tounkara, T. (2006). Critical knowledge map as a decision tool for knowledge transfer actions. Electronic Journal of Knowledge Management, 4(2), 129-140.

Ferreira, P. (2009). Linking knowledge management and leadership through knowledge mapping. In In 2009 International Conference on Management and Service Science (pp. 1-4).

Field, A. (2009). Discopering statistics using SPSS, Thrid Edition.

George, D., \& Mallery, P. (2005). SPSS for windows step-by-step: A simple guide and reference. Boston: Allyn and Bacon.

Hair, J. F., Black, W. C., Babin, B. J., Anderson, R. E., and Tatham, R. L. (2006). Multivariate data analysis.

Heckman, R., \& Guskey, A. (1998). The relationship between alumni and university: toward a theory of discretionary collaborative behavior. Journal of Marketing Theory and Practice, 6(2), 97-112.

Heide, T., \& Lis, L. (2012). Dynamic knowledge mapping: a visualization approach for knowledge management systems. In 45th Hawaii international conference on system sciences (pp. 4001-4010).

Jafari, M., Akhavan, P., Bourouni, A., \& Roozbeh, H. (2009). A framework for the selection of knowledge mapping techniques. Journal of Knowledge Management Practice, 10(1).

Jamil, N. I., and Ahmad, S. N. D. (2013). Mining operational databases to predict potential donors among University Alumni. In 2013 IEEE Business Engineering and Industrial Applications Colloquium (BEIAC) (pp. 922-925).

Jnr, B. A., and Pa, N. C. (2016). Mitigating Operational, Technical and Strategic Risk in ICT through Knowledge Codification Technique. Jurnal Teknologi, 78(8-2), 179-192.

Jnr, B. A., Majid, M. A., \& Romli, A. (2019). Emerging case oriented agents for sustaining educational institutions going green towards environmental responsibility. Journal of Systems and Information Technology, 21(2), 186-214.

Jnr, B. A., Pa, N. C., Nor, R. N. H., \& Josoh, Y. J. (2016). Knowledge mapping and multi-software agents based system for risk mitigation in IT organizations. Journal of Software Engineering and Intelligent Systems, 1(1), 61-80.

Jnr, B. A., Pa, N. C., Nor, R. N. H., \& Josoh, Y. J. (2017). Knowledge mapping process model for risk mitigation in software management. International Journal of Software Engineering and Computer Systems, 3(1), 1-16.

Kearney, K. S., Naifeh, Z., Hammer, T., \& Cain, A. (2019). "family" ties for Foster alumni in college: an open systems consideration. The Review of Higher Education, 42(2), 793-824.

Leslie, L. L., \& Ramey, G. (1988). Donor behavior and voluntary support for higher education institutions. The Journal of Higher Education, 59(2), 115-132.

Li, F., Miao, Y., \& Yang, C. (2015). How do alumni faculty behave in research collaboration? An analysis of Chang Jiang scholars in China. Research Policy, 44(2), 438-450.

Liang, J. (2007). The research and application of process knowledge map' constructing method. Journal of the Chinese Institute of Industrial Engineers, 24(1), 30-41.

Liu, J. and Cui, M. (2017). The analysis of civil aviation incident information based on knowledge map. ICTIS, 679-684.

Liu, J., \& Ge, L. (2013). A new integration mechanism for knowledge map of complex product development. In $10^{\text {th }}$ International Conference on Fuzzy Systems and Knowledge Discovery (pp. 520-525).

Mazambani, G., Reysen, S., Gibson, S., \& Hendricks, L. (2017). Socio-structural intergroup characteristics as predictors of intention to Join University alumni association. World Journal of Social Science, 4(2), 42-51.

Mehralizadeh, S., Dehdashti, A., \& Kashani, M. M. (2017). Evaluation of an undergraduate occupational health program in Iran based on alumni perceptions: a structural equation model. Journal of educational evaluation for health professions, 14(16), 1-7.

Menaouer, B., Khalissa, S. and Nada, M. (2015). The relationship between knowledge mapping and innovation process in FERTIAL company. $6^{\text {th }}$ International Conference on Information Systems and Economic Intelligence, 97-103.

Mitchell, S. M., \& Seaman, C. B. (2011). A knowledge mapping technique for project-level knowledge flow analysis. International Symposium on Empirical Software Engineering and Measurement, 347-350.

Moradi, R., \& Mirian, M. S. (2014). Role-based knowledge mapping: An operational decision support media for research purposes. In $6^{\text {th }}$ conference on information and knowledge technology (pp. 37-43). 
Moradi, R., Mahani, N. T., Eghbali, N., Ketabchi, E. and Mirian, M. S. (2012). Knowledge map as a decision support tool for expert finding in research-based organizations, Sixth International Symposium on Telecommunications, 1195-1200.

Nayman, R. L., Gianneschi, H. R., \& Mandel, J. M. (1993). Turning students into alumni donors. New Directions for Student Services, 1993(63), 85-94.

Numprasertchai, S., \& Igel, B. (2005). Managing knowledge through collaboration: multiple case studies of managing research in university laboratories in Thailand. Technovation, 25(10), 1173-1182.

O'Keefe, R. M., \& O'Leary, D. E. (1993). Expert system verification and validation: a survey and tutorial. Artificial Intelligence Review, 7(1), 3-42.

Peterson, H. and Roberts, T. (2016). Alumni e-networks: Using technology to engage net generation alumni. Presentation at the Higher Ed Blog Con virtual conference, 1-2.

Qing-lan, H., Gai, G. and Lan, G. (2016). Research on knowledge maps of life cycle cost control based on roles. Chinese Control and Decision Conference, 4009-4013.

Rattanamethawong, N., Sinthupinyo, S., \& Chandrachai, A. (2018). An innovation model of alumni relationship management: Alumni segmentation analysis. Kasetsart Journal of Social Sciences, 39(1), 150-160.

Rattanamethawong, V., Sinthupinyo, S., \& Chandrachai, E. A. (2015). An innovation system that can quickly responses to the needs of students and alumni. Procedia-Social and Behavioral Sciences, 182, 645-652.

Sabri, S. Q., Ahmad, A. M., and Abdulrazaq, M. B. (2017). Design and Implementation of Student and Alumni Web Portal. Science Journal of University of Zakho, 5(3), 272-277.

Schofield, P., \& Fallon, P. (2012). Assessing the viability of university alumni as a repeat visitor market. Tourism Management, 33(6), 1373-1384.

Scillitoe, J. L. (2013). The role of alumni attachment in the university technology transfer process. PICMET, 2397-2406.

Sharif, A., Kamal, M. M., \& Irani, Z. (2014). Visualisation of knowledge mapping for information systems evaluation: A manufacturing context. In $47^{\text {th }}$ Hawaii international conference on system sciences (pp. 478-3487).

Singer, T. S., \& Hughey, A. W. (2002). The role of the alumni association in student life. New directions for student services., 2002(100), 51-68.

Sivaprasad, K. (2012). Making best use of alumni associations for holistic development of engineering institutes. AICERA, 1-11.

Song, Y., \& Zhao, T. (2015). A Java-based knowledge mapping model. FSKD, 1345-1349.

Straub, D., Boudreau, M. C., \& Gefen, D. (2004). Validation guidelines for IS positivist research. Communications of the Association for Information Systems, 13(1), 24.

Sumathy, K. L., \& Chidambaram, M. (2014). Application of knowledge repository and mapping in knowledge management. World Congress on Computing and Communication Technologies, 203-207.

Suresh, H. R., \& Egbu, C. O. (2004). Knowledge mapping: concepts and benefits for a sustainable urban environment. ARCOM, 1-3.

Talab, A. H., Scholten, V., \& van Beers, C. (2018). The role of universities in inter-organizational knowledge collaborations. Journal of the Knowledge Economy, 1-21.

Teixeira, G. C. D. S., \& Maccari, E. A. (2014). Proposition of an alumni portal based on benchmarking and innovative process. JISTEM-Journal of Information Systems and Technology Management, 11(3), 591-610.

van Hattum-Janssen, N., Endedijk, M. D., Quadrado, J. C., Bernardino, J. and Rocha, J. (2017). Mind the gap: Why do technical alumni stay in the technical sector. 45 th SEFI Annual Conference, 1029-1036.

Weerts, D. J., Cabrera, A. F., \& Sanford, T. (2010). Beyond giving: political advocacy and volunteer behaviors of public university alumni. Research in Higher Education, 51(4), 346-365.

Wu, Y., Zhan, H. and Yu, J. (2016), Knowledge map application of business-oriented problem solving. 12 th International Conference on Natural Computation, Fuzzy Systems and Knowledge Discovery, 433-437.

Yildiz, A. E., Dikmen, I., Birgonul, M. T., Ercoskun, K., \& Alten, S. (2014). A knowledge-based risk mapping tool for cost estimation of international construction projects. Automation in Construction, 43(1), 144-155.

Yun, G., Shin, D., Kim, H., \& Lee, S. (2011). Knowledge-mapping model for construction project organizations. Journal of Knowledge Management, 15(3), 528-548.

Publisher's Note Springer Nature remains neutral with regard to jurisdictional claims in published maps and institutional affiliations.

Bokolo Anthony Jr . is currently a post-doctoral fellow at Department of Computer Science, Norwegian University of Science and Technology. He currently works on research and development in information systems. His research interest includes Sustainability, Smart City, Green IT/IS, Blended Learning and Knowledge Management. His email address is anthony.j.bokolo@ntnu.no

Short Biographies Author 